Portland State University

PDXScholar

Fall 11-25-2013

\title{
I'm Not Gonna Be Like That Guy: Exploring the Montana Meth Project Through the Eyes of That Guy
}

Jaysen Nicole Ferestad

Portland State University

Follow this and additional works at: https://pdxscholar.library.pdx.edu/open_access_etds

Part of the Public Relations and Advertising Commons, and the Social Control, Law, Crime, and Deviance Commons

Let us know how access to this document benefits you.

\section{Recommended Citation}

Ferestad, Jaysen Nicole, "I'm Not Gonna Be Like That Guy: Exploring the Montana Meth Project Through the Eyes of That Guy" (2013). Dissertations and Theses. Paper 1503.

https://doi.org/10.15760/etd.1517

This Thesis is brought to you for free and open access. It has been accepted for inclusion in Dissertations and Theses by an authorized administrator of PDXScholar. Please contact us if we can make this document more accessible: pdxscholar@pdx.edu. 
I'm Not Gonna Be Like That Guy:

Exploring the Montana Meth Project Through the Eyes of That Guy

\author{
by \\ Jaysen Nicole Ferestad
}

A thesis submitted in partial fulfillment of the requirements for the degree of

Master of Science

in

Sociology

Thesis Committee:

Melissa Thompson, Chair

Randy Blazak

Matthew Carlson

Portland State University

2013 


\begin{abstract}
Graphic images of meth addicts have swept across Montana in television, radio and print ads as part of the state's latest anti-drug campaign, the Montana Meth Project. From a labeling perspective, the negative portrayal of meth addicts in these ads has significant implications for meth addicts in terms of their reintegration. The unintended population of drug addicts potentially affected by public service campaigns has failed to gain attention in the literature despite the implications suggested by labeling theory. This poses a significant gap in our knowledge and understanding, which this study addresses through the voice of recovering meth addicts. This study explored the significance of the campaign with regard to the worldview of recovering meth addicts and the implications of this worldview with regard to their reintegration. In particular, the study examined 1) addict perceptions of the campaign's impact on community 2) addict perceptions of the campaign's personal impact 3) addict perceptions of the significance of social bonds 4) the implications of these perspectives from the theoretical standpoint of Labeling and Social Bond theory.

In-depth interviews were conducted among a sample of twenty recovering meth addicts at a treatment facility in Grenadier, Montana as well as one active meth user. This form of data collection was chosen due to the exploratory nature of the study as well the significance of perception suggested by the Symbolic-Interaction perspective (Cooley 1902). The study revealed that the Montana Meth Project does have a significant impact
\end{abstract}


on the worldview of the participants. When the participants believe the campaign has a positive impact on the community - creating awareness, understanding and acceptance the campaign is viewed as a tool in their reintegration. However, as the bulk of the findings suggest, when the participants believe the campaign has a negative impact stereotypes, labeling, stigmatization and differential treatment - the campaign is viewed as a barrier to their reintegration. With such a negative reaction in the worldview of the participants, the mainstream world including family, friends and the community did not appear to be at the forefront of their reintegration. Rather, a subculture of recovering addicts acts as the source of positive social bonds and the most significant in the reintegration of the participants. The findings of this study demonstrate the impact antidrug campaigns, and particularly scare campaigns using a public service approach, can have on the unintended audience of drug addicts. 


\section{Dedication}

This thesis is dedicated to my undergraduate professor and good friend, June Ellestad, who took me under her wing and inspired me to greatness. Everything I know and love about research and sociology began in her classroom and continued through various collaborative research projects. None of this would be possible if not for her belief in me. 


\section{Acknowledgments}

I would like to thank all of the participants for giving recovering addicts a voice. I would also like to thank my committee and particularly my advisor, Melissa Thompson, for sticking this out with me over the years and seeing to it that I finish. In addition, I would like to thank my family and friends who saved me from my own meth addiction. None of this would have been possible without them. 


\section{Table of Contents}

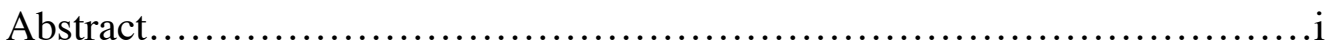

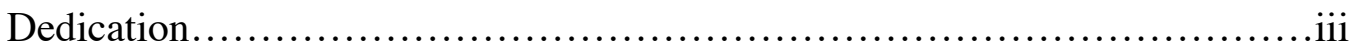

Acknowledgements.......................................................

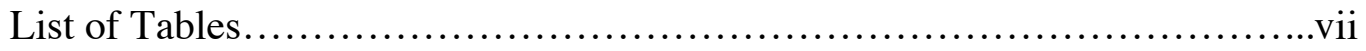

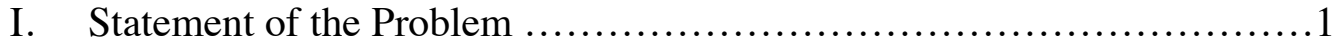

II. Literature Review..................................................... 6

The Meth Problem.................................................... 6

The Montana Meth Project.......................................... 8

Drug Prevention and the Public Service Approach......................12

The Stigmatization of Drug Addicts.................................18

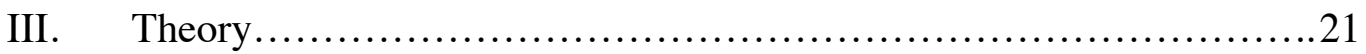

Social Reintegration................................................ 21

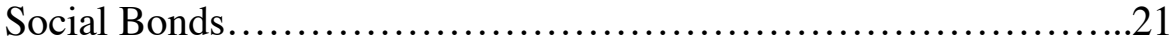

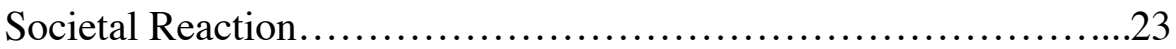

Self-Concept................................................ 24

Theoretical Framework:

Labeling Theory as Applied to Montana Meth Project..................25

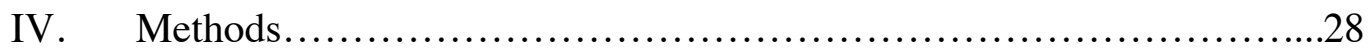

Community Setting ................................................. 29

Sampling, Sample Selection and Access............................... 31

Sampling Technique................................................ 34

Limitations......................................................... 34

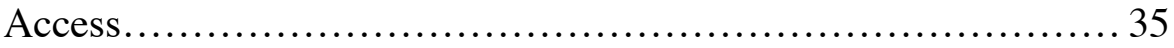

Recruitment....................................................... 35

Data Collection................................................. 41

Data Analysis......................................................

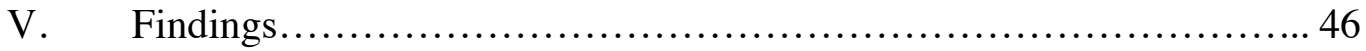

The Significance of Social Bonds.................................. 46 
The Significance of the Montana Meth Project........................51

Montana Meth Project as a Tool.................................52

Montana Meth Project as a Barrier............................. 56

VI. Discussion................................................ 70

Highlights of Findings......................................... 70

Program and Policy Relevance.................................... 78

Study Limitations............................................. 81

Future Research............................................. 82

Conclusion..................................................... 84

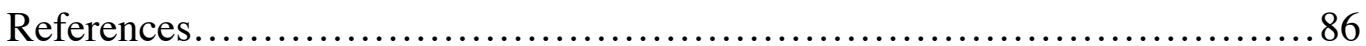

Appendix A: Consent Form.......................................... 90

Appendix B: Interview Guide......................................... 93

Appendix C: Timeline................................................... 96

Appendix D: Illustrations.............................................. 98 


\section{List of Tables}

Table 1: Demographics................................................44 


\section{Statement of the Problem}

With a meth pipe in his hands, a teenage boy tells his friends

"I'm going to try meth just once, I'm not gonna be like that guy," as he gestures toward the addict in the corner who is shaking and sweating with sores and scabs all over his body. Now, he has become the addict in the corner, deteriorating on his drug dealer's couch because he got hooked on meth. A young girl looks over at the now-wretched boy and says "I'm gonna try meth just once, I'm not gonna be like that guy."

This is one of the many advertisements broadcast throughout Montana in television, radio, and print ads, as well as on billboards and displays. The ads are part of a statewide prevention effort called the Montana Meth Project. The Montana Meth Project is a public messaging campaign, launched in 2005 to battle the state's methamphetamine problem (MMP Newsletter 2005).

Montana appeared to be in dire need of such an effort. As of 2005, Montana was overwhelmed by methamphetamine abuse. For example, by 2005 Montana ranked \#5 in the nation for meth abuse, $50 \%$ of inmates in Montana were incarcerated for meth-related charges, and $50 \%$ of foster care admissions were meth-related (Montana Attorney General's Office 2007, ONDCP 2008). As evidenced by this, the meth problem was costing the state an average of 100 million each year (Montana Attorney General's Office 2007). Thus, the Montana Meth Project was born. Aimed at reducing first-time methamphetamine use, the campaign uses hard-hitting advertisements to convey the devastating effects of methamphetamine use. The advertisements, founded on shock 
tactics, depict graphic images of addicts on the downward spiral of addiction. Media and politicians proclaimed the campaign to be one of the nation's most powerful anti-drug campaigns. While the campaign appeared to be the answer for preventing meth abuse in Montana, decades of drug prevention research have found past efforts of this sort to be ineffective (Anderson 2009; Crano and Burgoon 2002; Erceg-Hurn 2008; Shoenbachler and Wittler 1996; Varshavsky 2003). Further, as a result of their heavy reliance on public messaging, such campaigns reach audiences beyond that which was intended (i.e. at-risk and pre-use teens). The literature regarding the impact of anti-drug campaigns on unintended populations - drug addicts in particular - is virtually non-existent (Buchanan 2004). However, a better understanding regarding the impact of these campaigns on the unintended population of drug addicts is essential given the nature of the campaigns. Buchanan (2004) argues that the nature of anti-drug campaigns creates a 'war on the drug user' rather than a 'war on drugs' because such campaigns depict the drug user as the deviant enemy to be feared. From the labeling perspective, depicting the drug user as the deviant enemy results in a process of stigmatization and social exclusion from conventional society (Becker 1963; Braithwaite 1989; Buchanan 2004; Faupel, Horowitz and Weaver 2004; Goffman 1963). For those addicts attempting to re-enter the mainstream world as a conventional member of society, this may have dire consequences. An abundance of literature suggests stigmatization and social exclusion may hinder the reintegration of drug addicts and may lead them instead to continued involvement in the drug world (Adler 1993; Astone 1982; Buchanan 2004; Buchanan and Young 2000; Finkelstein 1994; Hartwell 2002; Lindsey, Korr, Broitman, Bone, Green and Leaf 2006; 
Link and Struening 1997; Reinarman and Levine 1997; Semple, Grant and Patterson 2005; Lemert 1951).

The Montana Meth Project depicts meth addicts as the deviant enemy to be feared. It warns young people not to be like 'that guy.' But what about 'that guy?' What do these advertisements mean for 'that guy' in light of labeling theory and past research on stigmatization? These questions deserve attention as the potential consequences of the campaign may exacerbate the very problem the state of Montana is attempting to ameliorate. Based on the nature of the Montana Meth Project, its potential consequences for meth addicts, and the gap in literature, the present study aimed to explore the significance of the campaign with regard to recovering meth addicts in Montana and their social reintegration. What is the significance of the Montana Meth Project with regard to the social reintegration of recovering meth addicts in Montana? In particular, the study addressed the following questions: 1) How do recovering meth addicts conceptualize the impact of the Montana Meth Project on the community? 2) How do meth addicts conceptualize the impact of the Montana Meth Project on themselves? 3) What is the significance of social bonds to these recovering meth addicts? 4) What implications do these perspectives have from the theoretical standpoint of Labeling and Social Bond theories?

A qualitative approach was used to explore these questions. This involved indepth interviews with recovering meth addicts utilizing addiction services at a drug treatment facility in Grenadier, Montana. This approach was used in order to capture the perspective of 'that guy' and discover the significance of the campaign in terms of the thoughts, feelings, beliefs and experiences of 'that guy' - recovering meth users. The 
study was conducted using the standpoint of recovering meth addicts in order to give them a voice as well as to understand the impact of the campaign on their worldview. Given that our worldview can shape our self-concept, social interactions, and behaviors (Cooley 1902, Goffman 1963), gaining an understanding of this worldview provides insight regarding the ability of these individuals to reintegrate.

This exploratory study offers a preliminary understanding regarding the impact of this anti-drug campaign on the unintended population of recovering meth addicts in Montana. While it would be difficult to draw any conclusions from this study alone, this study could draw attention to new avenues of research capable of informing policy and improving practice regarding the 'War on Drugs.'

The following chapters include a review of relevant literature and theory, methods used in the study, findings from the study and a discussion of the findings. Chapter II begins with an overview of the meth problem in Montana and a detailed description of the Montana Meth Project. This is followed by an overview of past drug prevention efforts that use the public service approach and relevant studies regarding these efforts. Lastly, this chapter looks at studies regarding the impact of stigmatization on social reintegration. Chapter III discusses theories regarding social reintegration, particularly social bond theory and labeling theory. This chapter concludes with a statement of the theoretical framework used in this study. Chapter IV contains the methods employed by this study. This chapter rationalizes the qualitative approach and explains why in-depth interviews were the most appropriate method. Further, the pros and cons of this method are discussed. This is followed by a detailed description of how the interviews were conducted and how the data were analyzed. 
Chapter V presents the findings of the study. The findings suggest the importance the recovery bubble to the participants and how the campaign is seen as a tool and as a barrier by the participants. In Chapter 6, highlights of the findings are discussed and related to relevant literature and theory. Policy and program relevance as well as avenues for future research are then discussed in light of the findings. Finally, the conclusion offers key points to be taken away from the study. 


\section{Literature Review}

\section{The Meth Problem}

Methamphetamine is a powerful and highly addictive central nervous stimulant (Hunt 2006; NIDA 2006). It comes in a powder form, which unlike many other stimulants makes it easy to smoke, snort, or inject intravenously. As a result, it gained popularity as a street drug, easy to use and abuse (Faupel, Horowit and Weaver 2004). When an individual uses methamphetamine, the drug releases dopamine in the brain, causing an intense feeling of euphoria (Hunt 2006; NIDA 2006). Methamphetamine is particularly attractive because of this feeling of euphoria, which has been compared to an intense sexual orgasm (Faupel et al.2004:86). Further, the high afforded by the drug lasts much longer than other stimulants, such as cocaine and crack (Faupel et al. 2004). However, the intense pleasure experienced by the user is followed by an intense "crash." This often leads to more use, in order to avoid crashing. In addition, users will often go on "runs" in which they sacrifice food and sleep while continuing to abuse the drug for days on end (NIDA 2006).

According to the National Institute of Drug Abuse (2007), methamphetamines addiction potential and destructive health and social consequences make its abuse particularly dangerous. Those who abuse meth face health problems such as malnourishment, sleeplessness, psychotic-like episodes, dental problems and brain damage (Faupel et al. 2004). In addition, there are severe social consequences associated with meth abuse including crime, violence, child neglect and abuse, unemployment and 
incarceration (Hunt 2006; NIDA 2006; NIDC 2005). Further, unlike cocaine, methamphetamine is man-made and the manufacture of the drug involves corrosive, toxic and highly combustible chemicals. This makes the preparation process extremely dangerous and potentially lethal not only to the meth "cooks" but innocent people in the immediate environment as well (Faupel et al. 2006). On top of that, there are environmental consequences including damage to property, water supplies, farmland and vegetation (Hunt 2006).

In the United States, meth was particularly problematic on the west coast and in Hawaii at the beginning of this decade. However, because meth is cheap and easy to make the problem continues to spread across the nation (Hunt 2006). According to the National Survey on Drug Use and Health (2006), ten million people over the age of twelve, abused meth in their lifetime and there were 500,000 current users as of 2005. Reports of meth abuse have since been on a downward trend; however the growing impact of meth abuse in the country is still evident in emergency departments, treatment programs and jails (Hunt 2006). In 2005, a 50\% increase was reported in the number of emergency visits related to meth abuse (Hunt 2006; NDIC 2005; NSDUH 2006). Further, treatment admissions in which meth was named the primary drug of abuse, have risen from 21,000 admissions in 1992 to 150,000 as of 2004 (NSDUH 2006; NDIC 2005). In terms of crime, $58 \%$ of law enforcement agencies reported meth as their number one problem in 2005 . Several states also reported as much as a $90 \%$ increase in meth arrests in the prior year (Hunt 2006; NDIC 2005).

While the entire nation has felt the impact of the meth epidemic, Montana is among a few states that have been particularly hard hit by the problem. For instance, 
between 2002 and 2005, Montana was among three states reported to have the highest rates of past year meth abuse (NSDUH 2006). The magnitude of Montana's meth problem is also reflected in treatment admissions, crime, drug arrests, incarceration, foster care, health care, and state funds. For instance, treatment admissions for meth use in Montana are double the national average (NSDUH 2006). In addition, the Office of National Drug and Crime Prevention estimates that meth-related crime in Montana is four times that of the national average; accounting for 73 percent of all drug-related crime, while nationally it only accounts for 17 percent (2008). One-third of Montana's federally sentenced defendants in 2007 committed a drug offense; more than two-thirds of these drug offenses involved methamphetamine (ONDCP 2008). Further, a staggering $50 \%$ of Montana's prison population is incarcerated due to meth-related crime (Montana Attorney General's Office 2007, ONDCP 2008). In terms of foster care, more than half of the children placed in foster homes are there due to meth-related abuse (ONDCP 2008). In terms of health care, emergency departments in Montana report more emergency room visits involving meth than any other drug (NSDUH 2006). In association with these consequences, the methamphetamine problem in Montana has cost the state millions. Based on such facts, it is evident why methamphetamine was declared the primary drug threat in Montana in 2005 (NDIC 2005).

\section{The Montana Meth Project}

The Montana Meth Project is a scare campaign that was launched in 2005 with the aim of significantly reducing meth use in Montana. The campaign came about in response to the staggering costs the state was facing as a result of their methamphetamine problem. While significant efforts were already underway in Montana such as 
restrictions on cold medicine, harsher penalties for selling and buying meth and the destruction of meth labs, this did not have a significant impact on the number of users (Siebel and Mange 2009). Thus, the Montana Meth Project was devised to reduce the prevalence of use by reaching young people before they try meth.

At the core of the campaign is a public service approach, which consists of television, radio, print, billboard, and Internet advertisements. The advertisements depict graphic images of meth users as unhygienic, dangerous, untrustworthy and exploitive to convey the dangers of meth (Erceg-Hurn 2008). The overarching message that permeates from the ads: "not even once." The purpose of these messages is essentially to effect attitudinal changes regarding meth use among Montana youth. Because most young people first try meth between the ages of 12 and 17, the campaign targets this age group, reaching an estimated 70 to $90 \%$ of teens 3 to 5 times a week with meth prevention messaging (Siebel and Mange 2009). The goal is to "unsell" meth, equipping youth with the facts about methamphetamine so they can make better-informed consumption decisions (MMP Newsletter 2005).

Since the MMP was initiated in 2005, there have been dramatic changes regarding meth use in Montana. According to Mike McGrath, the Attorney General of Montana, and based on findings from the 2007 Montana Youth Risk Behavior Survey, the following have been reported (Montana Attorney General's Office 2008:1):

- Lifetime meth use by teenagers in Montana has dropped 44.6 percent since 2005. This decline is greater than any other observed across all risk categories measured by the survey.

- Meth-related treatment admissions to state-funded facilities are decreasing. Despite overall treatment populations remaining virtually unchanged in the period between 2005and 2007, admissions for methamphetamine dropped 42 percent among patients 20 years old and under, and 24.5 percent for all patients. 
- Meth-related crime is decreasing. Meth-related crime increased by 21 percent from 2004 to 2005 , but dropped by 62 percent in the two-year period that followed through 2007.

- Additionally, the numbers of meth-positive probation/parolee violations continue a downward trend, indicating a sustained change.

- Progress is being made on meth's devastating social impacts. Meth accounted for 33 percent of all children in foster care, and over 50 percent of children in foster care for drug-related reasons in 2006. In 2007, these rates were both down 11 percent or roughly 100 fewer children.

- Overall meth use appears to be declining. Workplace drug testing shows that the decline in frequency of workers testing positive for meth in Montana is well ahead of the national average. Montana's overall rate of employees testing positive for methamphetamine fell 72 percent between 2005 and 2007, compared to a 44 percent drop nationally.

Based on these results, McGrath concluded that "combined with other enforcement, treatment and prevention efforts, the Montana Meth Project's education campaign has had dramatically positive results" (Montana Attorney General's Office 2008:9). Tom Siebel, the founder of the campaign, also concluded that the project was effective based on this evidence as well as survey results from the MMP attitude surveys. According to Siebel (2009),

Behind these changes in behavior are notable changes in attitudes about meth. Montana teens are aware of the dangers of taking meth, likely to disapprove of taking the drug, and likely to have had discussions with their parents on the subject. In fact, teens in Montana today view meth as more dangerous than heroin. More than eighty percent believe there are substantial risks in taking the drug. The great majority of Montana teens strongly disapprove of meth use, a level matched only by their disapproval of heroin use (413).

Siebel claims that these changes stem, in large part, from the Meth Project. The validity of this claim has met some resistance. "The Montana Meth Project, the media and politicians have portrayed the advertising campaign as a resounding success that has dramatically increased anti-methamphetamine attitudes and reduced drug use in Montana”, states David Erceg-Hurn (2008:256). However, Erceg-Hurn argues that the 
evidence used to make these claims is weak and not supported by the data. For instance, attitudes among Montana youth indicated strong disapproval of meth use prior to the implementation of the Montana Meth Project. Therefore, the campaign did not change attitudes but rather reiterated pre-existing ideas about meth. Findings from a study of the 1999-2009 Youth Risk Behavior Surveys (YRBS) also suggest that youth who were least likely to try meth in the first place were no less likely to try meth after the MMP was launched (Anderson 2009).

Erceg-Hurn (2008) further contends that there is no evidence that reductions in methamphetamine use in Montana are caused by the advertising campaign. Findings from Anderson's study support this claim. Based on the YRBS data, Anderson (2009) found that the drop in meth use among Montana teens is attributed to a preexisting downward trend. Further, Anderson (2009) found that when this preexisting trend is accounted for, the effects of the MMP on meth use are small and statistically insignificant.

Such critics suggest there are several alternative explanations for the drastic changes regarding Montana's meth problem including not only the pre-existing downward trend in meth use, but also policing efforts, restrictions on common ingredients used in meth manufacture and crackdowns on meth labs (Erceg-Hurn 2008, Anderson 2009).

Despite this information, many have jumped on board with Siebel's assessment of the Montana Meth Project as being effective. Due to the dramatic changes have been presumably linked to the MMP, the campaign has taken on a life of its own. It is now referred to simply as the Meth Project, and has become a template for several other states including Arizona, Idaho, Illinois, Wyoming, Colorado and Hawaii. Further, according 
to the campaign website (www.montanamethproject.org), additional states were expected to launch the campaign. Regardless of whether or not the campaign works, the Montana Meth Project can best be understood within the context of past drug prevention efforts of this sort.

\section{Drug Prevention and the Public Service Approach}

Public service announcements have a long-standing history of use in the realm of public health, addressing a range of issues from smoking and HIV/AIDS to child abuse, gun control and drunk driving. Aimed at changing public opinion, such announcements are intended to promote social change by educating the public on the issue at hand.

These announcements have become a popular medium for drug prevention in our nation, particularly in the past few decades. However, they began in the 1930's when the newly formed Federal Bureau of Narcotics conducted a "reefer madness" campaign. The campaign was one of the very first public service campaigns, launched by Harry J. Anslinger in his personal quest to combat marijuana. To sum it up, the bureau basically fed information from its files to newspapers, magazines and tabloids. In other words, they supplied the media with stories regarding the horrors of marijuana use such as the following excerpt,

An entire family was murdered by a youthful addict in Florida. When officers arrived at the home they found the youth staggering about in a human slaughterhouse. With an axe he had killed his father, mother, two brothers and sister. He seemed to be in a daze... He had no recollection of having committed the multiple crimes. The officers knew him ordinarily as a sane, rather quiet young man; now he was pitifully crazed. They sought the reason. The boy said he had been in the habit of smoking something which youthful friends called "muggles," a childish name for marijuana (Anslinger and Cooper 1937 [Faupel et al. 2004:53]). 
Such stories received strong reactions, essentially mobilizing public support and state laws prohibiting marijuana use (Faupel et al. 2004). Based on campaigns such as this as well as World War II propaganda campaigns, it was popular belief that the media had a powerful ability to shape public opinion and decision-making (Wartella and Stout [Crano and Burgoon 2002]). As such, there was a strong movement toward the use of mass media to create social change and improve health. However, in the 1950's this public service approach came under fire when researchers put the "power" of mass media to the empirical test. Katz and Lazarsfeld (1955) for instance, conducted a survey to determine how influential the media had been in shaping the public opinion regarding political votes. They found that personal contacts played the primary role in shaping public opinion and that the media did not play a significant contribution. Katz and Lazarsfeld concluded that the influence of the media was not significant given mediating factors such as one's social network. For instance, whether people buy what the media is selling heavily depends on whether the idea is reaffirmed or rejected within their social networks. The work of Katz and Lazarsfeld, as well empirical research that followed, was paramount in discrediting the direct power of media campaigns. As a result, media campaigns fell out of favor for some time (Wartella and Stout 2002). That is, until the 1980's when Ronald Reagan was elected president and waged the notorious 'War on Drugs.'

When Reagan was elected he made federal drug control a top priority prompting several significant developments in the world of drug prevention. Among these developments was the Partnership for Drug-Free America (PDFA), which was designed in 1986 to "unsell" drugs to the American public. It was considered the largest public 
service campaign in our nation's history, using all major media outlets, including TV, radio, print advertisements and the Internet. The PDFA was probably most notorious for its hallmark commercials, 'this is your brain on drugs.' In more recent years, PDFA advertisements have been focused on curbing marijuana use. The ads link marijuana use to unplanned pregnancy, misuse of guns and even terrorism (Erceg-Hurn 2008).

Another offshoot of the Reagan administration was the establishment of the Office of National Drug Control Policy. The ONDCP was established in 1988 to reduce illegal drug use, manufacturing and trafficking. In 1997, the ONDCP was responsible for the launch of the National Youth Anti-Drug Campaign (NYAD). According to Crano and Burgoon (2002), this campaign was one of the country's most ambitious media campaigns and certainly one of the most massive and expensive drug abuse prevention efforts. The campaign used mass media in an attempt to reach as many youth as possible to inform them of the dangers of drug abuse and encourage and facilitate their rejection of illicit drugs. Today anti-drug campaigns such as these make up the majority of all public service campaigns (Varshavsky 2003).

The National Institute of Drug Abuse (NIDA) among other agencies conducts evaluations of such campaigns. For instance, the NIDA conducts a nationally representative household survey of youth and parents living in the same household in regard to exposure of the NYAD campaign. The longitudinal study measures the impact of the campaign on attitudes, beliefs, intentions and behaviors on these youth and parents over time. As a result of mass research efforts such as this, we have substantial knowledge regarding the impact of media-based drug prevention efforts on their audience. For instance, research tends to suggest that the most effective efforts are those 
that "emphasize mild consequences rather than those offering graphic representations of the extreme" (Crano and Burgoon 2002:44). According to Varshavsky (2003), subtle emotional appeals tend to get through more than fear-based threatening messages because,

Thought provoking messages that appeal to reason tend to have a long term effect on behavior, whereas seemingly persuasive shock value from dramatic messages extends only short-term influence and does not stay with the viewer long enough to modify his or her behavior. Additionally, the shock value of a particularly spectacular message can be evaluated as much less likely to engage to the viewer personally, for in providing an extreme gruesome case the message evokes a sense of non-application of the communication, where the viewer comes to view the situation as too unlikely to be true. Whereas more subtle emotional appeals may make headway when viewers are able to analyze and appreciate personal pertinence (24).

Despite such evidence, anti-drug PSA's continue to draw on scare tactics to get their messages across (Schoenbachler and Whittler 1996; Varshavsky 2003). Recent studies continue to suggest the ineffectiveness of this approach. For instance, in a study of adolescent processing of anti-drug PSA's, Schoenbachler and Wittler (1996) found that threats of physical consequences such as damage to the brain and other drug-induced health problems are less persuasive and effective than messages regarding social implications such as scrutiny from friends. Further, Varshavsky (2003) conducted a study evaluating the effectiveness of the National Youth Anti-Drug Media Campaign. Based on a content analysis of fear-based television ads produced and aired for the campaign, Varshavsky found that most of the ads were not effective in reducing teen use and perception because they relied heavily on tactics which past research has suggested don't work (i.e. scare tactics). 
Aside from continued reliance on scare tactics, anti-drug PSA's also tend to be ineffective because the individuals they are convincing with their messages are not the individuals that need convincing. According to Varshavsky (2003), anti-drug messages are "most convincing to those who already believe in the dangers of drugs so the ads work in a reiterative rather than a preventative or rehabilitative fashion. As a result, segments of the youth population who are either most susceptible to drug experimentation, or at greater risk for developing truly disastrous habits, are virtually ignored, or else unreachable with the methods used" (22).

To reiterate, we have substantial knowledge regarding the impact of media-based anti-drug campaigns. We know what type of anti-drug messages appeal to the intended audience and what messages don't. We also know that anti-drug campaigns fail to make a significant impact on the intended audience. The problem is that all we know is what impact these campaigns have on the intended audience, i.e. at-risk youth. Yet we know nothing about the influence of these media-based campaigns on other populations. Due to the very nature of advertising, however, this type of campaign has limited control over who receives the messages they disseminate and how the messages are received. Therefore, such campaigns often reach a variety of audiences beyond that which was intended (Crano and Burgoon 2002; Crosbie 2003; Lancaster 2004; Yzer, Marco, Joseph N. Cappella, Martin Fishbein, Robert Kirkland, and Ahern R 2003). In other words, they reach not only at-risk populations, but also the "deviant" population (i.e. addicts) and the community in which they live as well. Unfortunately, because media-based drug campaigns target at-risk youth, research addressing the impact of such campaigns on other populations is virtually nonexistent. 
This gap in knowledge needs to be addressed, however, because so many of these media-based campaigns rely on scare tactics and more recently shock tactics, a form of 'reality' advertising in which horrific images of actual addicts are used to convey campaign messages (Faupel, Horowitz and Weaver 2004:412). Thus, when media campaigns use these deviant images to convey their messages, they are potentially creating stereotypes of drug addicts (Buchanan 2004; Furst et al. 1999). Further, because these campaigns reach a wide-scale audience, beyond that which was intended, these stereotypes could in turn lead to labeling and the stigmatization of drug addicts. Essentially, the war on drugs approach used by these campaigns becomes a war on drug users, as Buchanan and Young found with regard to a study on UK drug policy. According to Buchanan and Young (2000), "many problem drug users will have periods of stability in their drug use and many will have tried to move away from a drugdominated lifestyle. However, so demonized are this group, they remain trapped in the same lifestyle and with limited options available, many relapse and return to drug use" (414). Based on their study of problem drug users, Buchanan and Young (2000) conclude that anti-drug campaigns have added to the isolation and marginalization of this population.

With the exception of a few studies such as this, there is a lack of research regarding the direct impact of such campaigns on drug addicts. However, there is research regarding the impact of stigmatization on this population. According to the literature, stigmatization can have a significant impact on the social reintegration of drug addicts. 


\section{The Stigmatization of Drug Addicts}

Research suggests that the stigmatization of drug addicts affects their social reintegration in terms of self-concept, fulfillment of emotional needs, connection to and involvement in deviant and conventional social networks, and interactions with society. For instance, Furst and colleagues (1999) found that the stigmatized image of the "crackhead" acts as a symbolic constraint against use. It instills fear and anxiety in addicts who don't want to be identified with the traits their family, peers, significant others and the general public attach to the image of a "crackhead" (Furst et al. 1999). To avoid negative responses from society and their social networks, addicts therefore discontinue use and remove themselves from the deviant subculture (Furst et al. 1999). According to Furst et al. (1999), not only do they discontinue use and involvement, but they also come to take pride in not using, as is valued by their conventional social circles.

With the exception of these findings, however, the vast majority of research falls in line with labeling theory which suggests that stigmatization has a negative impact on the social reintegration of drug addicts. For instance, Buchanan and Young (2000) found that stigmatization and rejection were a common experience among recovering drug users and that such experiences had a deep and intrusive impact on the self-esteem of these users. Among other things, users reported feelings of unworthiness and second-class citizenship. Finkelstein (1994) reported similar findings with regard to a population of drug-using women. Drug-using women are often viewed as sexually promiscuous, weakwilled, negligent of their children, and irresponsible in their decisions to bear more children. According to Finkelstein (1994), this portrayal contributes to the negative and punitive attitudes surrounding drug use in women. Therefore, it is also a key to the 
heightened sense of stigma, rejection, and blame experienced by these women, which results in lower self-esteem, guilt, depression, and increased isolation. Based on a study conducted by Lindsey et al. (2006), these experiences of stigma, low self-esteem, and perceived lack of social support act as a barrier to treatment seeking and utilization. Not only do they act as a barrier to treatment seeking and utilization, but such experiences also play a role in the non-completion of treatment programs according to a study by Semple et al. (2005). Further, even if users do make improvements related to their illness - completing treatment, for example - Link and Struening (1997) argue that they are unable to reap the long-term benefits of treatment due to the stigmatization they encounter when they reenter the mainstream world. In fact Hartwell (2002) found that users, especially those faced with multiple stigmas, are adversely affected by their community living and adjustment due to the discrimination they face upon their return to the community (87).

Given what the literature suggests - stigmatization negatively affects drug addicts and hinders their ability to reintegrate - and considering the potential stigma created by media campaigns that rely on scare tactics, it is imperative we gain a better understanding of the potential impact such campaigns may have on drug addicts. Further, because the Montana Meth Project falls within the realm of media-based scare campaigns that uses horrific images of meth addicts to convey its messages, it has the potential to create a stereotype that leads to the stigmatization of meth addicts. As such, the campaign could be contributing to the continued involvement of meth addicts in the meth world and the problems that stem from that world including severe health problems, child endangerment, environmental dangers, and high rates of incarceration (Covey 2007). 
Given the gravity of these potential consequences specific aims of this study were not only significant in the intellectual realm but in the realm of public health as well. 


\section{Theory}

As the literature suggests, scare campaigns have the potential to play a significant role in the social reintegration of drug addicts. Theory regarding the process of social reintegration will provide a better understanding as to why this is.

\section{Social Reintegration}

There are several factors, which can influence an addict's ability to reintegrate as a member of the conventional social world. Based on various criminological theories, social bonds, societal reaction and self-concept are among the key influential factors involved in this process.

Social Bonds. To reintegrate, it is crucial for individuals to have conventional social ties. In other words, "the ones who get out are the ones who have a stake in something; the ones who have outside associations to family, children, pregnancy, school and legitimate work" (Williams 1989:131). When an individual feels a push to reenter the legitimate world, they can draw upon these ties to provide a bridge back (Adler 1989; Reinarman and Levine 1997). In essence, such ties are able to serve as the type of bonds to society described by Hirschi’s social bond theory (Hirschi and Gottfredson 1979). These ties create a foundation for which an individual can develop the following: attachments to family, friends and the community; commitment to conventional lines of action such as pursuing a career or working toward goals; involvement in conventional activities such as sports, school activities, religious groups and community organizations; 
and the belief in social norms and values such as respect, honesty and responsibility (Hirschi and Gottfredson 1979; Siegel 2006).

Empirical evidence supports this theory, suggesting that deviance is less likely among individuals with strong bonds of attachment, commitment and involvement to members of society with conventional lifestyles (Adler 1993; Hawkins [Brown 1979]; Siegel 2006; Williams 1989). In contrast, individuals who lack these conventional social ties are more susceptible to deviance. Due to weakened social bonds, these individuals often turn to people who have experienced similar problems as themselves. In the absence of positive associations, such bonds can lead to further deviant behavior and criminal involvement (Astone 1982; Becker 1963; Braithwaite 1989; Reinarman and Levine 1997; Siegel 2006).

Because of the stigmatic nature of the Montana Meth Project, an addict's attempts to form positive social bonds within the community may be futile. If an addict feels they are being judged or discriminated against, whether real or perceived, it may be difficult for them to form relationships and become involved in the community. Opportunities to take on a positive social role may be scarce due to community fear. Further, if positive social bonds do exist, the extent to which they aid in the addicts social reintegration is contingent on the nature of society's reaction to the addict as well as their perception of that reaction (Braithwaite 1989; Faupel et al. 2004). Social bond theory provides a significant perspective in this study. It acts as a guide, to discover what social bonds exist, how strong these bonds are and how they factor into the impact of the Montana Meth Project. 
Societal Reaction. According to labeling theory, regardless of whether an addict has social support and social networks to provide a bridge back to society, they are not out of the woods yet. Once the addict crosses that bridge, they are often faced with reactions from society, which can influence their ability to reintegrate (Braithwaite 1989; Faupel et al. 2004). In essence, they are exposed to what Braithwaite (1989) refers to as shaming. Reintegrative shaming communicates disapproval of the action within a continuum of respect for the deviant. In other words, the deviant is treated as a good person who has done a bad deed (282). There is an element of forgiveness and understanding in this type of societal reaction, which facilitates the process of reintegration. This falls in line with labeling theory, which suggests that deviance is less likely when it is respectful and focused on the act rather than the person and where disapproval is terminated by ceremonies of forgiveness and apologies (Braithwaite 2000: 288). Further, when shaming is reintegrative the propositions of Social Control (Bond) Theory are more likely to be true according to Braithwaite (288). This means that conventional attachments and other agents of conventional morality are more likely to reduce deviance in this atmosphere. However, the propositions of social control are less significant when shaming is degrading and disrespectful - when the deviant is treated as a bad person. When people shame us in a degrading way it poses a threat to our conventional identity. Braithwaite (1989) refers to this type of shaming as stigmatization. Labeling theory suggests that social agencies create stigmas that, in turn, become detrimental to the very problem they are trying to help, treat, or correct (Siegel 2004). Certain behaviors are labeled deviant, or "unacceptable," by moral entrepreneurs to send a clear message of disapproval for the behavior. These deviant labels then come to 
identify the characteristics of an individual rather than the act of an individual. This may hinder the addicts' ability to reintegrate because of the negative impact it has on their self-concept (Becker 1963; Braithwaite 1989).

When deviant labels come to identify the characteristics of the individual rather than the act of deviance, the individual takes on a new deviant social identity Goffman (1963) refers to as stigma. This stigma, according to Faupel et al. (2004:130), "powerfully changes their public identity." The result is a process known as role engulfment, whereby more and more of an individual's self-concept is centered on the deviant identity. Others have defined the individual as deviant and see them as an outsider therefore the individual comes to define themselves as deviants and see themselves as an outsider. In other words, the individual internalizes the label. The result is secondary deviance, in which the individual accepts and continues to act in accordance with the label bestowed upon them (Lemert 1951; Siegel 2006).

Self-concept. The Symbolic Interactionist perspective suggests our self-concept is deeply embedded in how others see us (Faupel et al. 2004). The self-concept of a drug addict, according to labeling theory, is the basis for which continued deviance or conformity will be established (Braithwaite 1989; Faupel et al. 2004; Lemert 1951). Thus, if others define us with certain labels, we will take on that identity and play the role associated with that identity (Braithwaite 1989; Lemert 1951). As such, it is crucial that an addict develop a positive self-concept including improved self-image and greater selfconfidence in order to reintegrate (Tongue and Turner 1988). In addition, they must develop a self-concept that allows them to identify with the dominant society, as a valuable member of society. For example, it is important for the addict to gain some 
sense of respect, dignity and belonging (Astone 1982: 117). According to Hawkins (1979) it is, therefore, important these individuals have opportunities to participate in conventional activities that provide a sense of usefulness, competence, personal power and belonging. If these individuals are not presented with such opportunities, however, it may negatively affect their ability to reintegrate. For instance, it could lead to a defeatist attitude and regressive behavior as Evard (1971) found. Further, such individuals may be unable to develop a sense of identity among the conventional world because the selfperception of these individuals include labels of "deviant" or "criminal" which tend to estrange them from the community (Adler 1993; Astone 1982:109). As a result, the individual continues to act in accordance with the deviant identity (Lemert 1951).

\section{Theoretical Framework Applied to Montana Meth Project}

To understand how the Montana Meth Project impacts the social reintegration of meth addicts, I used labeling theory as my theoretical framework. In particular, I looked at whether or not a perceived stigma existed among meth addicts as a result of the Montana Meth Project and what the implications of this perceived stigma would be.

As previously stated, labeling theory suggests that social agencies often create the very stigma that is detrimental to the very problem they are trying to help, treat or correct. With regard to drug addicts, this labeling process often begins with the very moral entrepreneurs that design propaganda to deter or scare people away from drugs (e.g. nonprofit organizations, political parties, and government agencies) (Buchanan 2004; Furst et al. 1999). According to Buchanan (2004), these moral entrepreneurs are responsible because the propaganda they use portrays drug users as the deviant enemy and conveys messages to society regarding what is believed to be the immoral and deviant behavior of 
drug addicts (Braithwaite 1989; Buchanan 2004; Siegel 2004). Such messages endow the whole drug population with a specific set of undesirable characteristics (Braithwaite 1989; Siegel 2006). Therefore, conveying these messages to the general public leads to negative stereotypes of drug addicts and bestows upon them such labels as 'crackhead,' 'methhead,' and 'pothead' (Furst, et al.1999). This labeling process has negative consequences for drug users. According to Buchanan (2004),

Those who are given a label such as 'druggie' or 'smackhead' find themselves not only socially marginalized and isolated, but subject to hostility and distrust. Within this climate, attempts by [addicts] to find understanding, friendship, and other opportunities to socially reintegrate with the wider population, tend to quickly fail (121).

As Buchanan alluded to, labeling negatively affects the core elements of social reintegration in that the process leads to negative societal reactions, poor self-image, a real or perceived lack of emotional support and isolation from conventional social networks. This study was not intended to discover whether drug addicts are actually judged, discriminated against and isolated. Rather this study was intended to discover worldview of the drug addict and whether they perceive themselves to be judged, discriminated against and isolated. Thus, the affects of labeling on the drug users selfconcept are particularly significant. According to Link and Phelan (2001), once the stereotype is in place it can affect the labeled person in ways that do not involve obvious forms of discriminatory behavior on the part of people in the presence of the stigmatized person. The individual develops conceptions of what it means to have that label. They form expectations as to whether individuals with that label will be rejected and devalued. When they identify themselves with label, the possibility of devaluation and 
discrimination becomes personal. The label becomes a part of their worldview, in which they experience lack of confidence, vulnerability and fear of rejection in the "normal world' (379). This leads some users to feel they cannot risk being honest with outsiders (Buchanan 2004; Furst et al. 1999; Link and Phelan 2001). According to Link and Phelan (2001), this leads to strained and uncomfortable social interaction, compromised quality of life, low self-esteem and unemployment among other things. Essentially, managing that damaged identity, in addition to the negative social reactions from society, produces a "cumulative disadvantage" difficult for users to overcome (Furst et al., 1999). Thus, they engage in stigma-coping strategies that ultimately lead them to 'reject their rejectors,' and turn instead to a deviant subculture of like-minded people who are similarly rejected by the wider culture (Adler 1989; Astone 1982; Becker 1963; Braithwaite 1989; Link, Francis and Struening 1989; Link and Phelan 2001; Reinarman and Levine 1997; Semple et al. 2005; Siegel 2006).

Labeling theory acted as the guide in this research process. In terms of research methods, the nature of the interview guide was derived from concepts within this theory. For instance, the guide was set up to reveal the addicts perspective: discovering any labels and stereotypes that exist, views of their own identity and their identity within the community, and what type of community reaction they have experienced. Further, as labeling theory would suggest, findings revealed a perceived stigma among the meth addicts in this study in relation to the Montana Meth Project. Insight regarding what implications this perceived stigma has on an addicts' reintegration are derived from this theoretical framework. 


\section{Methods}

This study was conducted among a sample of recovering meth addicts using qualitative research methods. Qualitative research methods were used to conduct this study for a couple of significant reasons. Given the lack of knowledge surrounding

public service campaigns and their impact on unintended populations, this study was very exploratory in nature. As such, a qualitative research design was necessary to gain a deeper understanding of the issue. Further, because qualitative research elicits subjective understandings and interpretation, such a design was well suited for this study, which takes the standpoint of the drug addict to understand public service campaigns.

According to Marshall and Rossman (2006), a qualitative approach such as this has limits and weaknesses. It involves personal interaction and therefore cooperation. Participants may be unwilling or uncomfortable sharing all the information the interviewer hopes to explore or the interviewer may not ask questions that evoke narratives from the participant due to lack of expertise or skill. Such issues were not present in this study, however, due to my personal knowledge and experience in the meth world. Through my background I was able to gain their trust, which I believe broke down barriers and melted away fear of judgment; in essence, evoking a willingness to share their stories. Further, my familiarity with meth use provided awareness as to what questions should be asked. Despite such advantages, it is possible that my background introduced personal bias, interest and values to the study. 
While it is important to acknowledge this as a potential weakness, it is also important to acknowledge recent feminist, postmodernist, and existentialist reconsiderations of research and the role of the researcher. Unlike conventional principles of social research, these perspectives accept and embrace the inevitable. Social research is not and cannot be entirely objective; nor should it be. According to Ferrell and Hamm (1998), "such perspectives insist research methods are, and must remain, inherently personal, political and partial endeavors. In doing so, they reintroduce the humanity of the researcher into the research process and make a case for critical, reflexive, autobiographical accounts and understandings - for openness to the 'subjective experience of doing research' - as part of the field research process" (24). Within this realm, the influence of my background would not be considered a weakness but rather an asset, enriching the study. While I agree, the importance of objectivity was not discounted with regard to the data and findings. Thus, several measures were taken to maintain the greatest degree of objectivity possible. For example, the interview guide was constructed to ask neutral questions that would not lead the participants in one direction or another. Further, during the interviews I was careful not to introduce my own opinions, thoughts or hypotheses surrounding the Montana Meth Project. As such, the data should reflect only the opinions, thoughts and ideas of the participants.

\section{Community Setting}

Because the Montana Meth advertisements reach the entire community in which the participants are trying to reintegrate, a feel for the community can provide a better 
understanding of the participants' perspective. Grenadier ${ }^{1}$ is a community of about 60,000 located in the heart of the Northern Rockies in Western Montana.

Demographically, Grenadier is by far a Caucasian community with other races only accounting for $7 \%$ of the population. The crime rate in Grenadier is relatively low with the majority of criminal activity involving petty offenses. In recent years however, there has been a rise in violent crime, presumably related almost entirely to substance abuse (ICPSR 2008). ${ }^{2}$

With regard to drug problems, Grenadier stands out among other communities in Montana. In fact it stands out among every region of the United States when it comes to illicit drug use. According to the Substance Abuse Mental Health Services Administration's (SAMHSA) most recent survey in 2006, Grenadier had the highest rate of illicit drug use in the nation with $13.8 \%$ of households reporting the use of illegal drugs in the past 30 days. The meth epidemic sweeping the state is at the forefront of Grenadiers drug problems while marijuana and cocaine have been major contributors (Vardi 2009). While this distinguished Grenadier from other Montana communities, it was not all that set it apart. This community was also unique in that the Montana Meth Project originated here. Thus, by the time the campaign was introduced to other communities across Montana, members of this particular community were already well acquainted with the campaign. As such, the community likely developed a heightened sense of awareness regarding the growing meth problem in Montana. As a long time resident in the community and barista at a local coffee shop, I noticed this in my personal

\footnotetext{
${ }^{1}$ To protect the confidentiality of the participants in this study, the name of the location has been changed. ${ }^{2}$ Citation includes the name of the actual community and therefore has been excluded.
} 
interactions with the community. The meth problem in the community was a frequent topic of conversation and the Montana Meth Project received a great deal of appraisal among community members.

\section{Sampling, Sample Selection and Access}

As part of the original research design, the sample population was intended to include active meth users and recovering meth addicts. The objective was to obtain a sample of active meth users via personal connections in the meth world and recovering meth addicts via treatment facilities. Unfortunately, the original plan fell through and I was unable to obtain a sample of active meth users. Despite approval by the Institutional Review Board to conduct interviews among this population, my recruitment efforts in the field were unsuccessful. My primary contact in the meth world quit using and moved to a nearby town to be with her family during the course of this research. However, she still maintained some contact with friends in the meth world thus there were alternate, albeit less reliable, sources to draw from if need be and there was still hope for getting at this hard to reach population. That is, until my contact and I discovered that the life circumstances of many of these potential participants had changed quite drastically during the past year. Several had been incarcerated, their charges ranging from drug distribution, trafficking and manufacturing to a standoff with the police. Others were seeking treatment at the time and could no longer be considered active in their disease while another had recently found out she was pregnant and quit using. I did, however, stumble upon one acquaintance still active in the meth world and willing to participate in the study. While this was great news, I hit yet another roadblock. Despite his own participation, the subject was uncomfortable providing leads to other potential 
participants for reasons later discussed. Therefore recruitment efforts came to a halt and with this one exception the sample population consisted entirely of recovering addicts.

This was somewhat detrimental to the research given the significance of this population's perspective. Research suggests that active users, who haven't sought treatment, may not be seeking treatment due to the very stigma this study is intended to address. Thus, if I fail to reach this population I may be missing a significant piece of the puzzle regarding the relevance of the Montana Meth Project to the reintegration of meth addicts.

Further, I felt it was important to capture these perspectives because of the unlikely awareness that existed among users regarding the campaign. Given meth users are often far removed from the real world, it would seem highly unlikely to find any that have even heard of the campaign much less have a perspective on it. However, during the time the campaign was implemented I was engaged in the meth world and learned of their awareness through personal interaction. Some were supportive; they wouldn't want anyone to have to go through what they are going through. Others were taken aback by it and thought the campaign was over the top. Then there were those that made fun of the campaign and its advertisements and treated it like a joke. On more than a couple of occasions I came across meth users who actually wore bracelets with the campaign logo, "not even once.” In addition, I found out later, some addicts actually sold meth in baggie's that bore the logo, "not even once." Regardless of what their opinions were, the most significant information I retained from these observations, was of course that meth users were aware of the campaign or at least the advertisements. No matter how isolated they had become or how much of the world they had shut out, they still managed to hear 
and see the advertisements everywhere and had contemplated how they felt about it. Thus, it would have been insightful to capture these perspectives in conjunction with those of recovering addicts if at all possible. Nevertheless the perspective of recovering meth addicts is considered sufficient amidst an uncharted territory of research.

Recovering meth addicts offer a significant perspective regarding the role of the Montana Meth Project in social reintegration. A core part of their recovery is learning to live a normal life in the real world without drugs. This includes returning to their families, getting housing, finishing their education, and getting normal jobs. In essence, they are attempting to do what Tongue and Turner (1988) refer as social reintegration: the process whereby drug addicts remove themselves from the world of drug use and try to adapt to living within the wider community without misusing drugs. Several elements are crucial for this process to be successful including a positive self-concept, emotional support, conventional social networks and acceptance among the wider community. However, because meth addicts are stigmatized by the Montana Meth Project attempts by addicts in Montana to reintegrate may be compromised. According to theory and research, stigmatization leads to low self-esteem and self-worth, real or perceived lack of emotional support, and rejection by the wider community; therefore hindering social reintegration. Thus, it is important to capture the outlooks, experiences, and interactions of these addicts, as they may be facing the stigma in their attempts to reintegrate. Further, in contrast to active users, there is a more promising chance of locating and acquiring a sample of recovering meth addicts given that they can easily be found in treatment centers and halfway houses. 
Sampling Technique. Because the objective of this study was to understand the perspective of a particular group of people, purposive sampling presented itself as the most appropriate technique. Purposive sampling allows the use of subjective information to locate a sample that fits the particular criteria sought after. Using this technique, treatment centers were targeted to locate and obtain a sample seeing as how treatment centers often house and treat meth addicts recovering from their addiction.

Limitations. While it would have been ideal to select participants from a random sample of treatment centers, only one treatment center was selected for several reasons including the lack of time and funds necessary for obtaining a more comprehensive and representative sample. Further, there are just not that many treatment centers to choose from. All together there are only five centers in Grenadier, three of which treat specific groups. For example, one center offers treatment specifically for Native Americans, another for women only and the third offers treatment specifically for teens. Thus, to get a representative sample the site selection was between the two remaining centers. One of these centers was in a hospital setting with an extensive list of treatment services, while the other was a residential program with more focused and intensive care, particularly with regard to meth addiction. Further, because of the nature of meth addiction it typically requires intense care. Thus, meth addicts are more likely to be found in the latter treatment setting. Based on this information, the residential treatment center was selected. This center primarily focuses on substance abuse treatment using a behavioral therapy model and consists of residential short-term treatment (30 days or less), residential long-term treatment (more than 30 days) and outpatient care. 
Access. To gain access to this particular treatment center, the director of the treatment center was contacted and a general overview provided regarding the proposed study and plan of action. In particular, the counselors at the center were provided with the general topic, the set of questions I would be asking as well as the informed consent the patients would be receiving. No changes were requested or made regarding the research design or interview schedule. Satisfied with the information provided, the center granted access for the study to be conducted. With the green light, a plan was devised to recruit addicts at the center. The goal was to recruit between twenty and thirty participants.

Recruitment. Recruitment took place at the treatment center during daily group sessions with patients receiving impatient and outpatient care. Approximately five or six different counselors were responsible for these various groups and the patients were divided among the counselors. Thus, before recruitment actually began I met with each counselor and set up a schedule whereby I would visit each group on various days during the workweek to recruit volunteers. The only criteria for participation, was that the participants constitute recovering meth addicts. The counselors who were very keen on their patients and their patients drug of choice, helped with this screening process. In the initial visit to each group, I would merely introduce myself, describe the study, and inform the patients what type of questions I would be asking. Further, the confidentiality of the study was emphasized as well as their right to decline participation. After my spiel, I would ask each group to inform their counselor if they were interested in participating. The counselor of each group would then allow me to come in for a couple of weeks and pull any recovering meth addicts from their group who had volunteered to participate. 
Following this regime, I interviewed patients from each group over the course of two months. During daily visits to the groups, I would drop in and ask the patients if anyone would like to do an interview that day. If there were any volunteers, the patients would then take individual turns following me to a private room to conduct the interview behind a shut door. Typically one or two interviews were conducted a day.

Originally as a means of protecting confidentiality, I planned to set up appointments with the participants so the interviews would take place outside the group meeting time. However, former studies had been conducted at the center in this fashion and the center preferred to do it this way. For one, it was more convenient for the participants. Rather than finding the time in their day to make it back to the center, they could just do it while they were already there. Further, given the open and intimate nature of group therapy, it was very probable the patients were already aware of each other's identity as an addict as well as personal information about each other.

Still, pulling participants from group had the potential to cause discomfort, as patients might not want others knowing they are participating in the study or providing me with information. This, in turn could create a bias in which I miss the perspectives of those patients uncomfortable with others knowing. To avoid this discomfort and address the potential bias, before volunteering the patients were made aware of how the participants selected; therefore, if they weren't comfortable with that set up they could talk to the counselors privately to set up a more confidential meeting time or opt not to participate. While addressing the bias surrounding other patients, there was still an issue regarding the counselors. The fact that the counselors were aware of who was being interviewed may have created some bias. The counselors' knowledge of the interviews 
has potential to cause discomfort among patients for several reasons. For example, they may worry if their participation will influence their counselor's treatment of them, or if they will face repercussions regarding what they reveal during participation. To address this concern, the patients were made aware from the very beginning that their participation is completely voluntary and their decision will in no way influence the counselors' treatment of them. Further, the patients were told that the counselors would not be given access to any information provided by the participants during the interview. Having taken these precautions, the patients appeared to be comfortable with the recruitment process. According to the counselors, nearly all who met the criteria as a recovering meth addict volunteered to participate with the exception of one who declined for unknown reasons.

Despite the patients' willingness and comfort with the recruitment process, difficulties did arise with regard to their willingness and comfort level during the interviews. Because I was not at the treatment center, except during group visits, it was difficult to build relationships or much of a rapport with the participants prior to the actual interviews. Without gaining the trust of the participants, barriers were likely to arise in which the participants didn't feel they can open up to me. As a result, it is possible that the interviews would only reflect what the participants were willing to tell me as a graduate student and not what is reflective of their true perspectives. To address this issue, I was prepared to share my own experience with meth in hopes that it would create a deeper connection with the participants and make them feel more comfortable opening up to me. Thus, when the participant would mention something in their experience that I could relate to either through my own experience or through the 
experience of my close friends, I would take the opportunity to mention it. For example, when participants talked about the hopelessness and helplessness they experienced, I took this opportunity to talk about the vivid memory I have of the hopelessness and helplessness my close friend experienced. She had lost her job, she had no place to live and her family was in agony with worry. Yet she was so wrapped up in it that none of this was enough to make her stop. I told the participants how she sat on the floor smoking a pipe, looked at me with this sadness in her eyes and said, "The only way out of this for me, is if I die or go to jail or get pregnant." Often times I would also tell them some memories I had of my own stint with meth. For example, I might tell them about the time I was driving to go get meth and every inch of me wanted to stop and turn around but I couldn't. I felt helpless. Relating their experience to my own or my knowledge of meth addiction appeared to evoke trust and therefore more open and elaborate responses from the participants.

While this was significant in building a connection with the participants, the greatest contribution came in the form of an old acquaintance that just so happened to be in treatment at the time; a woman I met a few years back that used to buy meth from a close friend of mine. This informant was crucial because we had a pre-existing relationship of trust and through her I could gain the trust of others. She was willing to vouch for me to others because she had witnessed with her own eyes my experiences with meth and because I had been there in the midst of her disease. She said, "When you were sitting there in the room, everyone was looking at you like [that] you know, and I was like, okay she's been there guys." She asked them not to judge me. She told them, in reference to me, "she's not clueless, she's been there and she's trustworthy." Coming 
from one of their own, this earned me a lot of credibility with the patients; something which was desperately needed because the patients apparently had some preconceived notions of me that could have hindered the interviews. According to my informant, they saw me as some naïve college kid who didn't know "shit" about meth. In her words, 'they thought you were just doing this to see what it's like to be on meth,' and everyone's like, 'you don't even know.' This was not surprising because as much as I tried to look the part, even when acting the part, I always came off looking like a college kid with an easy life. Being reminded of this, reiterated just how vital rapport would be to the internal validity of this study. Given their first impressions of me, it would have been very difficult to gain the trust of these participants. However, my prior adventures with meth and my pre-existing relationship with an individual in the group encouraged the participants to open up to me as they would another addict. With regard to the data, this increased confidence that the participants' responses were representative of their true perspectives; and therefore, increased the internal validity of the study.

Despite the good that came from relating to the participants, there was also potential for this to create biases in their responses. For example, they may feel they don't have to explain themselves to me assuming I already know what they are talking about. Looking through the interview transcripts, however, this did not appear to be the case except with regard to drug terminology. Participants would talk about "doing a gram" or a "ball" or "slamming dope" without explaining what those terms mean. The participants may have elaborated on such things, had they been talking to someone who was clueless about meth. Otherwise, my knowledge of meth use did not appear to create any bias in their responses. The only other difference I noticed from relating to the 
participants was their peaked interest in finding out who I am and what I am about. Often they would ask me questions about my use or how I quit or what I am doing now and my responses often evoked more elaborate responses from them as they attempted to relate to what I was saying.

Shifting the focus to active meth users, I ran into an old acquaintance while in the midst of recruitment efforts both at the treatment center and within the meth world. I knew this user through a fellow user and seized the opportunity to recruit at least one active meth user and make a possible connection to other users, which I had failed to do on my own. I mentioned the study to him while we were reminiscing and when it felt appropriate I asked him if he would like to participate. He seemed uneasy at first, so I described in great detail how I planned to keep his interview and his identity confidential, stressing the fact that his name would not be recorded in any way, shape or form. While this alleviated some anxiety, he was still concerned that the police would identify him through voice recognition if the interview were taped. Thus, I agreed not to tape the interview. Prompted by his anxiety of exposure, I suggested we hold the interview at a semi-secluded park rather than a public university campus. With a close and unassociated friend nearby in another car, we held the interview on a park bench down by the river. It was a public area but there were only two other cars in the parking lot and no one around so the privacy of the interview was upheld. The interview lasted approximately 40 minutes. In closing, I asked him if he would feel comfortable referring others to the study, whom he thought might be interested. He adamantly declined. Despite any assurance I gave him regarding confidentiality, he was afraid that any information regarding meth use or other users might somehow be connected back to him and he 
didn't want to risk it. Respecting his wishes, I was left without any leads and the recruitment of active users came to a close.

\section{Data Collection}

In-depth interviews were employed as the data collection method used in this study. As opposed to other qualitative methods (i.e. focus groups), in-depth one-on-one interviews guarantee a higher level of confidentiality and therefore less threatening environment; a priority given the sensitive and risky nature of the topic. Further, this method was chosen because it is intended to gain a deeper understanding of the participants' perspectives in their own words; which is significant given that participants not only create narratives with their words, but social worlds as well. Thus, in-depth interviews generate data, which give an authentic insight into their experiences and provide access to the meanings they attribute to their experiences and social worlds. Because this study is intended to capture the addicts' perspective of the Montana Meth Project, their thoughts, feelings, attitudes, beliefs and experiences surrounding the campaign can be captured using this particular method. According to Marshall and Rossman (2006), reliance on interviews as the sole method of data collection can be limiting because there is no way to check the [external] validity of the information. While there may be no way to determine whether the narratives of the addicts reflect actual accounts, this study is not intended to gather factual information but rather to uncover the subjective reality of the participants.

To guide the interviews a semi-structured format was used as this allows the participants the freedom to present their perspective while at the same time allowing the researcher to seek answers that are of particular interest. As such, the interviews were 
conducted using an interview guide. The interview guide consisted of open-ended questions specifically aimed at addressing the participants' knowledge of the Montana Meth Project [e.g. have you heard of the campaign; what do you know about it], exposure to the campaign [e.g. have you seen or heard the Montana Meth ads; how often do you come across the ads], and perspective of the Montana Meth Project [e.g. how do you feel about the ads; the campaign in general; how do you think the ads/campaign affect people's perceptions of meth addicts]. The interview guide also aimed to address the nature of the addiction [how long did you use for; how often], and the reintegration of recovering meth addicts [e.g. what factors influenced your decision to come to treatment; describe what recovery has been like; what factors have helped in your recovery; have you encountered any barriers; what factors would further aid in your recovery; what factors would hinder your recovery]. Lastly the interview guide aimed to understand the role of the Montana Meth Project in the lives and reintegration of meth addicts [e.g. have the ads affected you personally; what you share with others about your experience; the way others treat you; your relationships; do you think the campaign has influenced your recovery].

Interviews were conducted among a sample of twenty recovering addicts and one active user. Each interview lasted approximately 30 to 40 minutes. The interviews were taped and transcribed. Upon transcription the tapes were then destroyed.

Among the sample $60 \%$ were male and $40 \%$ female. Ages among the sample ranged from 19 to 45 with an average age of 30 . Representing the majority of the sample, there were fifteen Caucasians (75\%), followed by two African Americans (10\%), two Hispanics (10\%) and one Native American (5\%). 
Among the 21 participants, eight had less than a high diploma, seven had attended college and four of those seven had a college degree of some sort. More than $50 \%$ of the participants held down blue-collar jobs (e.g. mechanic, cook, nanny, electrician), while another $30 \%$ of the participants were unemployed. Further, the average income of the participants was less than $\$ 10,000$ a year. With regard to family, the majority of participants $(75 \%)$ were either single or divorced and more than half of the participants had children.

Based on meth admissions in Montana, the sample of recovering addicts appears to be representative of the target population with regard to age, gender and race. According to the Substance Abuse and Mental Health Administration's (SAMHSA) treatment episode data set, $53 \%$ of all meth admissions in Montana were male and $47 \%$ female. The majority of admissions were between the ages of 21 and 30 (44.1\%). In addition, Caucasians made up $79.3 \%$ of all treatment admissions, while Native Americans made up 16\%, African Americans only .7\%, and other categories 3.6\%.

With regard to active meth users, my sample is not representative because there is only one participant. Inclusion of this data is significant nevertheless given the opportunity to get a glimpse into the world of an active meth user. While I cannot make generalizations based on this participant's responses, his perspective can still provide useful insight and provide ideas for future research regarding active meth users. 


\begin{tabular}{|c|c|c|c|c|c|c|c|c|}
\hline ID & AGE & $\begin{array}{l}\text { GEN- } \\
\text { DER }\end{array}$ & RACE & $\begin{array}{l}\text { MARI- } \\
\text { TAL }\end{array}$ & $\begin{array}{l}\text { CHILD- } \\
\text { REN }\end{array}$ & $\begin{array}{l}\text { OCCU- } \\
\text { PATION }\end{array}$ & $\begin{array}{l}\text { IN- } \\
\text { COME }\end{array}$ & $\begin{array}{l}\text { EDU } \\
\text { CATION }\end{array}$ \\
\hline 1 & 22 & Female & $\begin{array}{l}\text { African } \\
\text { American }\end{array}$ & Single & 1 & Housekeeper & $>10 \mathrm{~K}$ & $\begin{array}{l}\text { Earn } \\
\text { GED }\end{array}$ \\
\hline 2 & 30 & Male & Caucasian & Married & 1 & $\begin{array}{l}\text { Network } \\
\text { Tech }\end{array}$ & $30 \mathrm{~K}$ & $\begin{array}{l}\text { Bachelor' } \\
\mathrm{s}\end{array}$ \\
\hline 3 & 41 & Male & Caucasian & Married & 3 & Carpenter & $10-20 \mathrm{~K}$ & $\begin{array}{l}\text { HS } \\
\text { Diploma }\end{array}$ \\
\hline 4 & 24 & Male & Caucasian & Single & 0 & Mechanic & $10-20 \mathrm{~K}$ & $\begin{array}{l}\text { Some } \\
\text { HS }\end{array}$ \\
\hline 5 & 25 & Male & Caucasian & Single & 0 & Cook & $10-20 \mathrm{~K}$ & $\begin{array}{l}\text { GED/ } \\
\text { Vo-Tech }\end{array}$ \\
\hline 6 & 29 & Female & Caucasian & Married & 3 & Health Care & $>10 \mathrm{~K}$ & $\begin{array}{l}\text { HS } \\
\text { Diploma }\end{array}$ \\
\hline 7 & 23 & Female & Caucasian & Divorced & 0 & Nanny & $>10 \mathrm{~K}$ & $\begin{array}{l}\text { Some } \\
\text { College }\end{array}$ \\
\hline 8 & 38 & Male & Caucasian & Divorced & 2 & Electrician & $20-50 \mathrm{~K}$ & $\begin{array}{l}\text { Associate } \\
\text { 's }\end{array}$ \\
\hline 9 & 25 & Female & Caucasian & Married & 2 & Unemployed & $>10 \mathrm{~K}$ & GED \\
\hline 10 & 26 & Male & Caucasian & Single & 0 & Carpenter & $10-20 \mathrm{~K}$ & $\begin{array}{l}\text { HS } \\
\text { Diploma }\end{array}$ \\
\hline 11 & 28 & Female & Hispanic & Single & 2 & Deli Counter & $10-20 \mathrm{~K}$ & GED \\
\hline 12 & 27 & Female & $\begin{array}{l}\text { Native } \\
\text { American }\end{array}$ & Single & 3 & Unemployed & $>10 \mathrm{~K}$ & $\begin{array}{l}\text { Some } \\
\text { College }\end{array}$ \\
\hline 13 & 37 & Female & Caucasian & Single & 1 & Unemployed & $10-20 \mathrm{~K}$ & $\begin{array}{l}\text { Some } \\
\text { HS }\end{array}$ \\
\hline 14 & 29 & Female & Caucasian & Single & 2 & Unemployed & $>10 \mathrm{~K}$ & $\begin{array}{l}\text { Some } \\
\text { College }\end{array}$ \\
\hline 15 & 34 & Male & Caucasian & Single & 0 & Unemployed & None & $\begin{array}{l}\text { College } \\
\text { Degree }\end{array}$ \\
\hline 16 & 45 & Male & Caucasian & Single & 0 & Unemployed & None & $\begin{array}{l}\text { Less than } \\
\text { HS }\end{array}$ \\
\hline 17 & 19 & Male & Hispanic & Engaged & 0 & Unemployed & $>10 \mathrm{~K}$ & $\begin{array}{l}\text { Some } \\
\text { HS }\end{array}$ \\
\hline 18 & 32 & Male & Caucasian & Single & 0 & $\begin{array}{l}\text { Self- } \\
\text { Employed }\end{array}$ & $>10 \mathrm{~K}$ & $\begin{array}{l}\text { HS } \\
\text { Diploma }\end{array}$ \\
\hline 19 & 26 & Male & $\begin{array}{l}\text { African } \\
\text { American }\end{array}$ & Single & 0 & Cashier & $>10 \mathrm{k}$ & $\begin{array}{l}\text { Some } \\
\text { Vo-Tech }\end{array}$ \\
\hline 20 & 33 & Male & Caucasian & Single & 0 & Unemployed & $>10 \mathrm{~K}$ & $\begin{array}{l}\text { Associate } \\
\text { 's }\end{array}$ \\
\hline 21 & 36 & Male & Caucasian & Single & 3 & Drywall & $10-20 \mathrm{~K}$ & $\begin{array}{l}\text { HS } \\
\text { Diploma }\end{array}$ \\
\hline
\end{tabular}

Table 1: Demographics 


\section{Data Analysis}

Data analysis was conducted using a grounded theory approach. Thus, data management was inductive and consisted of summarizing, synthesizing, and sorting the data using open, axial, and selective coding. Open coding refers to the first coding of qualitative data in which a researcher examines the data to condense it into preliminary analysis categories or codes for analyzing data. Axial coding then refers to the second coding of qualitative data in which the researcher organizes the codes, develops links among them, and discovers key analytic categories. Finally, selective coding refers to the last pass at coding in which a researcher examines previous codes to identify and select illustrative data that will support the conceptual coding categories that he or she developed (Neuman 2003 [Glazer and Strauss 1967]). In essence, the interviews and field notes gathered were examined, coded, and re-examined to discover emerging themes and concepts from the data. A symbolic interaction perspective to labeling was drawn upon in order to aid in this coding process. The criteria established to aid in this analysis pertains to the implications of the Montana Meth Project on the social reintegration of Montana meth addicts, as it is understood in the literature. Thus, the criteria include the management of self-image, beliefs about community perceptions of meth users, expectations of community members, experiences with community members and experiences related to reintegration. The coding and analysis of the data was carried out using a qualitative analysis software package called QSR NVivo®. 


\section{Findings}

The purpose of this study was to explore the significance of the Montana Meth Project from the perspective of recovering meth addicts and understand how these perspectives tie into their social reintegration according to Social Bond Theory and

Labeling Theory. In particular, the study aimed to understand how meth addicts conceptualize the impact of the Montana Meth Project on the community and themselves, thereby illuminating the implications of these perspectives with regard to their worldview and ultimately their re-entry into society. Their re-entry into society and the campaigns significance in this re-entry cannot be fully understood without first exploring the potential significance of social bonds in this re-entry. Thus, the findings are reported in two sections: Significance of Social Bonds and Significance of the Montana Meth Project. The second section is broken down into two opposing themes - Montana Meth Project as a Tool and Montana Meth Project as a Barrier. The findings draw from excerpts of recovering meth addicts to best illuminate their viewpoints.

\section{The Significance of Social Bonds}

Research and theory suggest that the likelihood of social reintegration is greater among individuals with strong conventional attachments, commitment to conventional lines of action; involvement in conventional activities; and belief in social norms and values (Adler 1993; Hawkins [Brown 1979]; Hirschi and Gottfredson 1979; Siegel 2006; Tongue and Turner 1988; Williams 1989). If such bonds are absent or weak, attempts at reintegration may fail. As a result, such individuals turn to people they can identify with, 
who have experienced similar problems as themselves; thereby, leading to further deviant behavior and criminal involvement (Astone 1982; Becker 1963; Braithwaite 1989; Reinarman and Levine 1997; Siegel 2006).

Findings suggest that conventional social bonds did exist among the participants. However, these bonds fell within a narrow scope. In terms of attachments, Hirschi's Social Bond Theory refers to ties among family, friends and community members that lead a conventional lifestyle. Family did not emerge as a major theme in the participants' conventional attachments. Only seven of the participants acknowledged family members as significant attachments and pillars of support in their recovery. A few of the participants appeared to have a strong sense of attachment to family. In particular, the parents played a significant role in getting them into treatment and being there for them through the process. Otherwise, there was a perceived lack of family attachments and support among the participants. A number of reasons accounted for this perception. Seth, for example, reported not having a family at all. For Quin, the closest thing to family was the mother of his brother's child, who according to him is "always dragging me into their stuff." For others, relationships with family members were severely strained. For example, Harley was not allowed to see his family. His wife put a restraining order on him, which prevented him from being near her as well as their children. Lastly, conventional attachments to family did not exist because these relationships fell within scope of deviant attachments. Nikki, for example, spoke of the struggles she faced finding bags of meth at the home of a family member. Similarly, Frankie's family continued to drink in front of her despite her fragile state of recovery. 
In terms of friends and the community, the core of their attachments in this realm appeared to be within the recovery community (i.e. Alcoholics Anonymous, Narcotics Anonymous). Most of the participants acknowledged some type of friendship or support network specifically with other recovering addicts. These networks appeared to create a strong conventional attachment for the participants. In terms of social networks outside of the recovery community, they appeared virtually nonexistent. Of those that did have social networks outside of recovery, such relationships were very weak because the participants felt judged by their status or feared being judged. Thus, within such networks they engaged in coping strategies such as rejecting their rejectors and concealing their identity (Buchanan 2004; Lindsey et al. 2006; Semple et al. 2005). For example, Layna stated, “I just kind of hid it. I didn't want them to know because I didn't know what they would say or think." However, deviant social networks were also virtually nonexistent. Most of the participants reported removing themselves from such networks in their attempts to remain clean and sober. The findings suggest the participants lack certain conventional attachments (i.e. family, friends) but have strong conventional attachments in terms of a recovery community.

In terms of commitment to conventional lines of action, this refers to such things as pursuing a career or working toward a goal. Half of the participants reported having conventional aspirations and goals. While almost half of the participants were unemployed, it was evident that acquiring a job was a common goal among the participants. Other goals and aspirations included finishing a GED, starting a family, going back to school and trying to get their children back. For most of the participants, 
goals were of a more personal and immediate nature (i.e. staying clean and sober and repairing broken relationships).

With regard to belief in social norms and values, this refers to such things as respect, honesty and responsibility. Several of the participants exhibited a sense of belief in social norms and values in their statements. Harley, for instance, felt as though his family was beginning to trust him again and appeared to take pride in that. In addition, Owen and Kendra acknowledged the importance of being responsible and accountable. Many of the participants reported feeling shame and guilt for their actions while they were in their addiction and welcomed the opportunity to make amends for such actions. According to the participants, the 12-step program used by recovery programs such as AA, would provide the vehicle for such an amends.

It takes a month or two for your head to totally clear up and it was tough not being able to see my kids and realizing the things I've done, all the people I've hurt. All the people I've lied to. It's where I went and that's tough to deal with, but on the flip side I've got something to look forward to. I've got a lot of amends to make that I look forward to doing.

This amendment process would essentially give them the opportunity to engage in a sort of 'forgiveness' ceremony' mentioned by Braithwaite (1989) as an essential part of 'reintegrative shaming.' Through such a ceremony they gain a sense of trust and respect from others, and therefore a belief in conventional norms and values.

Last is the involvement in conventional activities, which refers to such things as sports, school, religious groups and community organizations. Three of the participants were attending school at the time and half of the participants were employed. Two of the participants reported being involved in sporting activities such as swimming and biking. 
However, the most common theme with regard to involvement in conventional activities consisted of their involvement in recovery programs such as NA and AA. Most of the participants reported being involved in such programs. This was mandatory for several as a result of legal trouble. However, most of the participants stressed the significance of involvement in these programs with regard to their recovery and reintegration.

These findings suggest that the participants do have strong bonds of attachment, commitment, involvement and belief in the conventional world; that is, in the recovery world. The recovery community provided the ‘bridge back' as Adler (1993) described it. Many of the participants described ways in which the recovery community provided a bridge back. For instance, Josh met his boss inside the rooms of AA and Gina struggled to find housing until a long-standing member of AA took her in. Further, within these recovery programs, the participants found other means of conventional activities as well. "We go on float trips and have barbecues and volleyball tournaments," said Eddie. In addition, they found support from these networks that other networks could not provide. Within this network, they share their experiences without fear of judgment. They identify with one another and band together because they have experienced similar problems.

I'm surrounded by people that have all used so they know what I'm going through and they're supportive. -Eddie

I think the important thing for me is being around people who are sober and who strive for recovery. I mean I'll be around my husband's family and they'll be drinking and I can't be around people like that. I have to keep myself in recovery-based stuff. -Frankie 
Being in a good environment... at home or with people that have gone through the same thing as me helps. My mom she doesn't understand the addiction. -Nikki

As these excerpts suggest, the recovery community provides a conventional 'bubble' so to speak. Essentially, it provides the strong social bonds necessary to social reintegration, as suggested by Hirschi's Social Bond Theory. Outside of this bubble, however, bonds to family and other conventional members of society appear to be weak. The strong bonds within the recovery community hold promise for the addict's social reintegration nonetheless. However, as Braithwaite (1989) and Faupel et al. (2004) suggest, they are not out of the woods yet. Despite having a bride back to the conventional social world through this recovery community, they still face reactions from the world outside the community. These reactions may fall within a reintegrative nature or stigmatizing nature and can impact their reintegration regardless of the social bonds in place. As Braithwaite (1989) suggests, the propositions of Social Bond Theory are more likely to be true when shaming is reintegrative. This means that conventional attachments and other agents of conventional morality are more likely to reduce deviance in this environment (288). Thus, the next section explores the nature of the societal reaction deemed a significant factor in reintegration by labeling theory.

\section{The Significance of the Montana Meth Project}

This section discusses the societal reaction from the perspective of the participant. In particular, it explores the nature of shaming that takes place as a result of the Montana Meth Project. It must be emphasized that this study does not measure shaming, as it actually exists in the world, but rather shaming as perceived by the participants. Their worldview of the shaming that takes place is just as significant as any shaming that 
actually occurs with regard to their social reintegration (Astone 1982; Braithwaite 1989; Buchanan 2004; Lindsey et al. 2006; Semple et al. 2005). Conflicting worldviews were discovered among the participants, as to the significance of the campaign on the community and their own lives.

Montana Meth Project as a Tool

The central themes that emerged in the data cast a negative light on the Montana Meth Project. However, the participants did perceive one major benefit of the campaign: raising awareness of the severity of the meth problem in Montana. The participants perceived several benefits to the meth addict in conjunction with this awareness.

\section{Raise Awareness}

Almost half of the participants agreed that the campaign has been beneficial in bringing attention to the meth problem in Montana, which they emphasized, is staggering.

I know it [Montana Meth Project] has been going on for the last couple of years and that it's a good thing that needs to be happening cause meth has kind of taken over Montana and it's a big epidemic and its traveling all over the world and its causing a lot of problems and killing a lot of people. -Gina

Gina, among other participants, believed that despite the gravity and extent of the meth problem in Montana, it had been given little acknowledgment or discussion until the Montana Meth Project was introduced to the state. Due to the aggressive nature of advertising used by the campaign (i.e. frequent television, radio and billboards ads), the participants felt as though the meth problem was brought to the forefront and people were practically forced to acknowledge its presence in Montana. Not only did the campaign 
bring the meth epidemic to the attention of Montana people, but opened the lines of communication regarding the topic. Many of the participants' spoke of conversations with family, friends, loved ones and even random strangers that occurred as a result of the various ads they had seen or heard. And with people statewide now being informed of the problem and open to discussion, the participants appeared to view the campaign as a tool in their reintegration. Essentially, they believed the campaign played a positive role in their community's reaction to meth addicts and as a result in their personal lives and recovery.

\section{On Community: Compassion and Understanding}

According to five of the participants, the Montana Meth Project played a positive role as far as generating compassion and understanding among the community. These participants felt as though the campaign was able to educate the community on the nature of meth addiction. Equipped with this education, the community would be more understanding of the struggles a meth addict faces. As Ivy stated, "people now have an understanding of why it's so hard to quit.” Further, because the community understands their struggles, the participants hope or believe this will translate into a desire and willingness to help.

I would hope that the community would, well that it would make them want to help more, somebody who is at that stage or any stage of meth...that they would want to help them because it's a scary thing. And just making the community more aware has probably made it a lot easier to talk about and get help for. -Frankie

I'm not sure that I've shared a lot with the community but I think it would be easier for me now because I think meth has been put out in the open a bit more and it's talked about and understood and people know what it is and they realize 
how much it affects the communities and so it's not like I feel like I'm the one person in Montana that is affected by this. People understand, so when you have a bigger group of people backing you up it makes it easier. -Owen

Frankie and Owen suggest a possible ease in coming back from the depths of meth addiction, which they attribute to the Montana Meth Project and its impact on the community. They spoke of how this occurred in their own personal experience.

\section{On The Addict: Support}

The participant's perception of the community reaction is reflected in their views of their own experiences. They experienced compassion and understanding, which they credited to the campaign. According to Frankie,

Now that everybody has become more aware of it, I have received more compassion I think...now that people are getting a better understanding as to what happens, how much it's around...so people, especially people in that division of addiction, are more sympathetic and more compassionate to the problem.

Further, the participants believed that such compassion and understanding made people less judgmental of them. Instead, they found that people were more concerned about their wellbeing, as the following statements reflect:

I think they [the ads] have had an influence on how my mom perceives it. She is more understanding of the fact that some of those behaviors are an inevitable part of addiction. She sees the addiction so she is less apt to judge me or to blame me for the things that I've done. She understands it is part of the disease.

-Owen

People that I know that don't use, they don't really understand but they are starting to more and more. Instead of 'friggin drug addicts' you know, they are more like 'they 
need to get help.' And it's easier now to talk to people I think. -Josh

These excerpt suggest that the campaign has a reintegrative nature from the perspective of these participants. Braithwaite contends that shaming is reintegrative when the individual is seen as a good person who has done a bad deed and whose actions are disapproved within a continuum of respect for the individual (1989). Owen and Josh perceive this to be true in their experiences. The campaign allows people, like Owen's mother, to see that the horrific behavior is a consequence of the addiction and not a reflection of who they are. Further, because people recognize they are not bad people, they do not exhibit fear and disgust but rather a desire to help the addict. This desire to help could be interpreted as a sense of forgiveness from the community. Labeling theory suggests labeling is reintegrative when there is an element of forgiveness (Braithwaite 1989).

Based on the voice of these participants it would appear as though the Montana Meth Project has had a positive impact on the lives of recovering meth addicts. By bringing awareness and education to the community, the campaign has created an atmosphere of acceptance, empathy, support and encouragement. Such an atmosphere is necessary for shaming to be reintegrative. Thus, the campaign may facilitate the reintegration of these individuals.

Despite the promise this holds, the views of these participants were the exception to the findings. While the participants acknowledged and praised the effort put forth by the Montana Meth Project to raise awareness of the problem, criticism of the campaigns approach and tactics emerged as a resounding theme in the data. 


\section{The Montana Meth Project as a Barrier}

The majority of the findings tend to suggest that the Montana Meth Project generates shaming of a stigmatizing nature rather than reintegrative nature. This is apparent in the major themes that emerged.

\section{The Negative Portrayal}

Owen was among the participants critical of the campaign, saying "it is great they are getting it out there, but I don't know that their tactics are the best." In particular, criticism of the campaign tactics, centered on its inaccurate representation of meth addiction. Approximately $75 \%$ of the participants found the portrayal of meth addicts in the campaign to be inaccurate and extreme, as some of the following excerpts suggest:

I think they are kind of far-fetched. -Ivy

It's a little too extreme. - Harley

I think they go overboard. -Layna

I'm a recovering meth addict and nothing there shows the picture of my life and addiction. It's not the picture.

-Michelle

I think some of them are pretty extreme, personally. I don't know what other people have done. Certainly, I've never torn myself up or start looking all smashed up or anything. Never sold my body for it, things like that. They are fullblown as far as the advertising and trying to get the message across. -Kendra

I think they portray a lot of it to be wrong. I've never seen anybody that bad. There's the one with the plucking of the eyebrows. That one is totally ridiculous. I've never seen anyone pluck their eyebrows out to where they bleed. I've plucked my eyebrows but not to that point. I don't agree with it really. I know meth addicts that are doctors, I know meth addicts that are caseworkers, and the only people I've ever seen that even look close to that is somebody who 
didn't care about taking care of themselves and a lot of meth users I know, including myself, constantly brush their teeth, floss, and wash their face. We care about our appearance. -Nikki

Show me people that look like that...just way far-fetched. They're just people in make up [in ads]. Put a real person on there. That's just phony. - Wyatt

As these statements suggest, the participants could not identify with the depiction of a meth addict as is portrayed by the Montana Meth Project. They acknowledged that perhaps there are some people at the later stages of addiction that look like that, but on average that is not the reality. They appear to feel as though the campaign associated meth addiction with poverty and a low-income sector of people. As Michelle stated, "they see us as the bum on the street or the lone body... stereotyping as people in the trailer park and that's not necessarily so, because there are people extremely up there that aren't necessarily like that." In fact, some reported knowing functioning members of the community who were addicted to meth. For example, Nikki reported knowing doctors and caseworkers addicted to meth. Further, the campaign associated certain behaviors (i.e. violence, abuse, self-mutilation, theft) with a meth addict, which the participants felt do not reflect the actions of an average meth addict. Thus, they felt the campaign painted an unrealistic picture of the meth addict.

Among other things, the lack of accuracy in portrayal of meth addicts, led many of the participants to feel the campaign could not be an effective form of prevention.

I think the ads are accurate for a certain population of meth addicts but I think the problem is that the majority, especially the younger kids that are seeing the commercials, they are interacting with meth addicts that are in no way to that advanced stage of the addiction as far as appearance and personal behavior. So I think in a way that 
kind of turns them off. Its another of those, 'well that's not how it is, that can't happen to me,' because it doesn't look like the meth addicts they know, their friends, themselves, whoever. -Owen

I would obviously encourage them [young people] not to do it, but a lot of their perception is what they get off the $\mathrm{TV}$, what they see. 'I never wanna look like this guy that I seen on the TV'... but that doesn't even happen. I mean I believe in what they're doing especially after having lived a lot of that. I think it's the wrong approach by far, especially for people already doing it. It's definitely, in my opinion, the wrong approach. It had no affect on me using, or those around me, at all. I mean we knew people like that but again it was a very rare circumstance to that extreme. - Billy

The participants appeared to feel as though the campaign should focus less on the extreme and more on the true consequences of meth addiction, such as: abandoning cares, neglecting obligations, the hopelessness, the isolation, having a criminal record that will haunt them the rest of their lives, emotional losses, personal losses, and the rock bottom every addict experiences. As Billy stated, “They're picking the very extreme people, plucking out their eyebrows, and it's kind of a shame because there are a lot of hidden signs. I mean just with average people and what they are destroying, that's not as vicious as what they [the ads] are portraying, but still definitely harmful to those around them." Billy elaborates,

They need to get more in touch with what goes on behind the scenes, what it does to your job, what it does to your employment, what it does to your family. It'd be nice to see a shift more in that direction. It's more personal, more what you lose. You tear apart your family, more along that aspect rather than the physical bodily experience and what they've seen on TV. I mean look, look what I've lost and what it's destroyed...nothing physical but look at all the pain that's in my life. So I mean to me the Montana Meth Project isn't even effective. In my experience when I start 
thinking okay maybe I can use just once, I start thinking about my wife, my son, you know, my business, and not someone getting in the shower and plucking their own eyebrows out.

On a similar note, Harley said,

Come to an IOP [intensive outpatient] meeting and listen to everybody's story. When you are face to face with people, it's different than radio or TV. You know, TV or radio can seem a little made up. When I was high, I didn't ever go kicking in a Laundromat [Montana Meth Ad], telling people I wanted money, or beating up my mom [Montana Meth Ad], or anything like that. Being around people that can share their experiences and tell you where it leads and tell you how great it is on the other side...the TV commercials, they don't do that.

Frankie brought home the point Billy and Harley were making. In her words, "I've been trying to do some research on how your brain comes back and you can get any piece of what you lost back and some people do, but emotionally I'll never be the same." Thus, the participants believe the campaign, while having good intentions, is misdirected and therefore ineffective; primarily, as a result of its inaccurate portrayal of meth addicts.

\section{Stereotypes}

Criticism of the campaign's representation of meth addicts goes beyond its ineffectiveness, however. It hits home for the participants. According to Ivy, "It's a scary thing and there is a way out once you've been there, but I think it [Montana Meth Project] gives people an opinion before they are educated about it." The literature suggests that in order to deter or scare people away from drugs, moral entrepreneurs tend to rely on a portrayal of drug users as the deviant enemy, stereotyping them with a set of undesirable characteristics (Braithwaite 1989; Buchanan 2004; Siegel 2006). Several of the 
participants suggested the campaign paints an unfair picture of the meth addict, casting a stereotype on the population as a whole.

It kind of gives stereotypes. -Ivy

It [Montana Meth Project] makes a person who uses for fun look like a bad person. They're stereotyping everyone that uses into a bad person. -Wyatt

It kind of puts them into one category. Meth addicts are all over the place, in the workplace. People you wouldn't even think were meth addicts are meth addicts. It kind of put a stigma on them. -Perry

As these excerpts suggest, the participants felt the campaign does a disservice to meth addicts by endowing the whole population with this set of characteristics. Of the 21 participants, 14 felt these stereotypes had a significant impact on how meth addicts are seen and treated. With regard to the community, the central theme that emerged was labeling.

On Community: Labeling.

Approximately two-thirds of the participants felt the community uses images designed by the Montana Meth Project as a rule of thumb to categorize and label meth addicts. In their words:

I think it casts a little negativity on someone who's a recovering meth addict. Someone might think of a particular ad, all the kids screaming they are gonna kill their parents, and think well everyone must be violent. -Trey

They think you might just evolve as this horrible person because of what people see. -Ivy

People think we are, or well I'm not a meth addict anymore, but that they are just schizophrenic horrible people. -Kendra 
People think we are all junkies and we're not. They think we are all bad. We are all criminals. And we're not. I know there are some people out there that are thieves that use meth and break into people's houses and steal shit to get dope, but I think they also need to educate people that we're people. -Nikki

Meth addicts are seen as the deviant enemy from the perspective of these participants. They are seen as bad people and there is no distinction made between their actions and who they are as people. This is what Braithwaite refers to as stigmatized shaming, whereby, the offender is treated as a bad person and is shamed in a disrespectful and degrading way. According to the participants, this is apparent in the community's perception of meth addicts.

They frown down upon meth addicts. -Dale

It makes society look way down on meth addicts, which whether that's the way it should be or not, I don't know. -Charlie

People obviously look down on meth addicts, almost like how people view gay marriages. People are disgracing it. It's almost like people view meth addicts almost worse. -Gina

In addition to the community's perception of meth addicts, it is apparent in community's reaction to meth addicts. The participants perceive an atmosphere of fear and paranoia in their community, which they attribute to the campaign.

It's detrimental in a lot ways because it stereotypes a certain population of meth addicts and increases paranoia of meth addicts and makes the stigma on meth addicts, worse...so detrimental. -Nikki

I think it's put an imprint in a lot of peoples' mind, that's how meth is. Those are the signs to watch for and if you 
know anybody on meth, be careful, because they are going to rob you in a convenience store.-Billy

I think people are more scared of meth addicts and what a meth addict might do than they are willing to help. I think it's a little too extreme. They don't offer any sort of followups on the ads, radio or TV that says if you'd like to help... or there's not a lot of community programming to see what the community can do to help the problem. Everybody's paranoid of meth. The community is really scared of meth and in a way they have a right to be. It's not like meth people go around passing out flowers and helping old ladies across the street, but I think they need to be educated more as far as how to help people not just how to close them out. It's not like we're lepers. -Harley

As these excerpts suggest, the participants believe the community is terrified of the meth addict and therefore they are not embracing meth addicts with open arms. Rather, the community shuns them and shuts them out. From the eyes of the participants, this relates back to the campaign. The campaign created the stereotypes the community is using to label and react to meth addicts. Essentially, a stigma exists as a result of the campaign and Braithwaite (1989) would argue that they are permanently left with this stigma. Several of the participants reported personal experiences in which they dealt with this stigma.

\section{On the Addict: Stigma and Differential Treatment}

According to Goffman (1963), when deviant labels come to identify the characteristics of the individual rather than the act of deviance, the individual takes on a new deviant social identity referred to as stigma. More than half of the participants experienced a stigma in terms of their identity and interactions with others. With regard to identity, the participants' felt the stigma associated with their identity as a meth addict 
continued to be imposed on them despite their attempts at a conventional identity.

Charlie attested to this,

In my case, I'm a very responsible upstanding citizen for over 20 years in my community and I only did meth for a year and that's the only thing anybody remembers. They think all these bad things and they don't remember before.

In addition to feeling as though they were haunted by this deviant identity, the participants perceived judgment from others when they were open about their former identity as a meth addict and even their identity as a recovering addict.

When people ask me what I've been doing or whatever I just assume they know something about my history so I'm like 'well I went to treatment and got clean' and if they didn't know I was messed up on drugs the last three years, they're like 'oh, you went to treatment' and all of a sudden they look at me like I'm a piece of shit now and it's like 'sorry I even told you.' So I do risk the chance of telling them if they didn't know but if I don't say anything they are going to think I'm still a drug addict, you know. So it's really hard to know what to say to people. It's like what do I say and then my best friend is always like 'I wouldn't tell people that if I were you.' -Gina

When I first started going to these meetings [Narcotics Anonymous] I had to tell my boss and my shop supervisor where I was going and I felt bad and I didn't know what they'd think. That was really hard for me. And there's one guy there that gives me crap. He jokes around like, 'oh you druggie, you druggie, you druggie.' -Dale

There are people judging me and I think I don't care really what they think and this is my issue, but people are so judgmental. It does affect me in a way...like when you get a new job or do some of the things you want to do, because people are prejudice. -Layna

I was living in motel rooms and I could afford to live in motel rooms instead of renting a house... which no landlord is going to rent to a meth addict. -Seth 
As these quotes suggest, the participants experienced labeling and differential treatment when sharing their identity with others. They felt as though they were treated in accordance with the labels imposed on them; treated like 'tweekers' and 'criminals.'

Further, the participants experienced rejection associated with the identity, as the following excerpts suggest:

I know that since I got arrested for meth and people found out that I used it, I see people that I used to be casual friends with and they'll just turn around and walk the other way and I'm pretty sure that's why. -Harley

At my work some of the other guys, who were supposed to be my friends, would walk away from me when we would be working together and we were in front of the manager or even just like at the casino or something... because they didn't want anybody to know they were friends with a tweeker. -Wyatt

Being identified as a meth addict led these participants to feel as if they are seen as nothing beyond that identity and resulted in perceived judgment and rejection from others. As such, the participants reported feeling less inclined to share their identity with others for fear they would be judged and treated differently.

People always are judgmental and pass judgment and it's hard to...you know you lose face. I mean how embarrassing is it to know that someone you met has shot up. And I have hepatitis and it's like when I talk they look for the after effects. I feel that a lot. I mean not so much when I'm dealing with treatment providers but just like if I'm in front of some high-standing person in the community I would not want them to know because I'd probably get judgment passed right away...cause if you just tell people, 'I used to be a user,' people look at you different. -Frankie

As Frankie's statement suggests, some of the participants experienced shame (i.e. embarrassment) in association with the identity. In association with the fear of 
community reactions, this made it more difficult for them to open up to others;

particularly, those they cannot identify with such as the 'high-standing person' Frankie spoke of. Overall, these personal experiences speak to the existence of a perceived stigma among the participants; in the way they are viewed personally and in the way they are treated in their social interaction with others.

The Montana Meth Project appeared to play a significant role in these personal experiences with stigma. Approximately half of the participants referred to the campaign with regard to their stigmatized identity and the resulting differential treatment they received from the community, friends and family. While the other participants reported experiencing stigma and differential treatment, they did not directly link these experiences to the campaign. However, these participants did not exclude that link as possible reason for their experiences. They just did not make the connection. Of the participants who did, however, they appeared to feel as though people used the stereotyped image created by the campaign in order to label them personally.

At my mom's house, it [the ad] was the one with the kid going in and stealing, digging through his mom's purse. I was watching it with my mom and she's like, 'hey there you are.'-Owen

My daughter, she's five years old...the ads affected her. She kind of just liked the eyebrow thing. I remember her saying, 'mommy does that' and I'm like 'whoa, wait a minute, I'm not like that.' -Nikki

Those around me, those who know me, know I don't do meth, but people in the community, that don't really know you...I think it [MMP] definitely shapes their perspectives. Especially, I will get accused of doing meth or I was doing meth and I will just fall into those categories you see on $\mathrm{TV}$, which I think is pretty slanted until you actually get to know what exactly happened. -Billy 
As these excerpts suggest, the participants appeared to feel that people close to them or in the community were profiling them based on the Montana Meth Project's advertisements. Further, the participants reported feeling judged by others on the basis of the ads.

I don't know about the ads cause people are looking at me knowing that I have a drug problem, and they're looking at the ads, and they're like, 'oh gross.' That's exactly why I think the ads are just out of control. It's like I know all the anger and ugliness but that's not... people that have never been there when they look at that it's disgusting...that's not really how it works but inside you feel that way.

-Gina

I think it [MMP] probably gives people some wrong impressions about me. I don't think I was as far into the meth as some people that were and probably deserved that image. It's just that people in the community get this image and you can tell they're talking about you or something.

- Charlie

I just get tired of hearing that I'm a tweeker like in the ads. It's a small community. Everyone says I'm a 'tweeker.'

People give me the cold shoulder, whisper. I just think it's a bad deal. -Wyatt

The participants see themselves as being judged because people automatically associate them with what they have seen and heard in the advertisements. People talk about them behind their back, look down on them and reject them due to their identity and how it is portrayed by the campaign. Gina offers another testament to this:

People have become more defensive. People don't trust you. I went to the first Meth Project meeting in town and I was high when I was there and they knew who I was. My former boyfriend was one of the main dealers in town. I was listening to what they were saying and they basically portrayed everybody as 'thieves,' which is not true. It was just horrible. And here I am standing in a community of 
people talking down on meth users. And they consider us monsters and we're not. We're people. We're people too.

And I thought it was very unfair. They need to do a different approach. They need to cut back on the harassment cause that just makes it worse.

Gina suggests the approach of the Montana Meth Project 'just makes it worse.' According to labeling theory, she would be right. Labeling Theory suggests that labeling is reintegrative when it focuses on the act of deviance rather than the individual and includes an element of forgiveness. However, labeling makes matters worse when it is stigmatizing (Braithwaite 1989). This notion exemplifies a resounding theme among the participants. Essentially, the campaign had a negative impact on these participants, with the exception of a few. From their perspective, it has portrayed them inaccurately, thereby creating stereotypes with which others used to label them. The labels imposed on them include 'tweekers,' 'monsters,' 'druggies,' 'lepers,' 'thieves,' and 'junkies.' They believe they are treated in accordance with these labels and stigmatized. This stigma entails judgment, shame and rejection, experienced by the participants. Whether or not this stigma is real, these participants perceive it to be real. The mere perception of stigma has significant implications.

According to the Symbolic Interaction Perspective, society is in the mind. We see ourselves as others see us and act accordingly (Cooley 1902). Therefore, if a stigma is perceived we are going to internalize that stigma and act accordingly (Adler 1993; Astone 1982; Goffman 1963; Lemert 1951). We develop conceptions of what it means to have that stigma (Link and Phelan 2001). When we feel the stigma is being applied to us personally, we develop expectations of how we will be treated (Semple et al. 2005). Even if we never experience direct mistreatment, we develop beliefs in which we expect we 
will be rejected, devalued and perceived as less worthy because we are identifiable by a particular characteristic (Semple et al. 2005: 376). This labeling process has a negative impact on the self-concept. With regard to the drug addict, theory and research suggest that once the label becomes part of the self-concept, it can be detrimental to their social reintegration. It can result in a self-fulfilling prophecy in which the individual acts in accordance with the label bestowed upon them and returns to a deviant subculture (Astone 1982; Braithwaite 1989). Even if labeling does not result in a self-fulfilling process whereby the individual becomes the label, it can still hinder their reintegration in terms of their ability to break into mainstream society. They may not identify with the label, yet the label has created difficulty in their attempts to lead a conventional life because they believe others identify them with that label. This results in experiences of guilt, low self-esteem, depression and isolation. In association with this, it results in loss of family, friendships, employment and housing (Braithwaite 1989; Buchanan 2004; Goffman 1963; Lindsey et al. 2006; Link and Phelan 2001; Semple et al. 2005). In the long run, it may not be a self-fulfilling prophecy that leads them back to a deviant subculture but their inability to break into mainstream society because of this stigmatized identity they believe has been imposed on them. In addition, due to the isolation and loss of ties associated with having a stigmatized identity, the social bonds necessary for social reintegration are weakened. With regard to these participants, this implies that the social bonds created through their recovery community may not suffice in light of the stigmatized shaming they face in connection with the Montana Meth Project. As a result, attempts at reintegration on the part of these individuals may be compromised. While the 
participants may not become 'that guy,' being labeled 'that guy' may create a barrier to their reintegration. 


\section{Discussion}

What is the significance of the Montana Meth Project with regard to the social reintegration of recovering meth addicts in Montana? This question was explored through the eyes of recovering meth addicts using Labeling Theory and Social Bond Theory. In particular, the study explored the addict's perception regarding the impact of the campaign on the community and themselves. In addition, the study explored the significance of social bonds in relation to the impact of the campaign. In this section, a highlight of the findings will be discussed to provide an overview of the findings. The significance of these findings will then be discussed in terms of their contribution to the literature. This chapter concludes by discussing future research with regard to the study and policy and program relevance.

\section{Highlights of the Findings}

The findings in this study offer several insightful themes as to the significance of the campaign as well as the role of social bonds in the reintegration of meth addicts. The findings suggest the participants have weak social bonds with regard to family and conventional social networks outside of their recovery community. However, the recovery community appears to provide all the necessary social bonds for reintegration including attachment to conventional members of society (i.e. members of AA or NA), involvement in conventional activities (i.e. river floats and BBQ's), belief in conventional values (i.e. respect gained through forgiveness ceremonies such as the $9^{\text {th }}$ step), and commitment to conventional goals (i.e. staying clean and sober). While some of the 
participants reported having strong bonds to family, the recovery bubble appeared to be the most significant in their sobriety. In essence, the recovery bubble provided a subculture of like-minded people with similar experiences that a deviant subculture might provide according to labeling theory. However, it does so within the conventional realm, making it very significant in terms of the reintegration of these participants. Despite this, the literature suggests the participants are not out of the woods yet (Braithwaite 1989; Faupel et al. 2004). Inevitably, the participants face societal reaction outside of their recovery bubble that either reinforce or diminish the significance of the social bonds provided by the bubble.

The findings suggest that the Montana Meth Project plays a significant role in societal reaction, at least in the eyes of the participants. Contradictory to the major themes in the findings, the perspectives of a few of the participants suggest the campaign creates a positive societal reaction. Being more aware and educated about the meth problem in Montana (as a result of the campaign), these participants believe the community gains the ability to empathize with meth addicts. These participants believe the community understands the struggles of being a meth addict and wants to help in their reintegration as a result of their empathy. Further, the participants feel the advertisements in the campaign offer a glimpse into the behavior of a meth addict, thereby making it easier for the community to distinguish between the behaviors of an addict and the addict as an individual. In essence, the campaign appears to operate as a form reintegrative shaming - whereby the individual maintains respect and disapproval is focused on their actions rather than their character. As such the campaign is viewed as a tool for reintegration in the eyes of these participants. 
With the exception of these five participants, the findings predominately suggest the opposite is true of the campaign. The campaign is not a tool in their reintegration, but rather a barrier to reintegration. This is because, as the majority suggested, the campaign operates as a form of stigmatized shaming. It puts out a negative image of the meth addict to the community, which they consider to be extreme, inaccurate and ineffective. This image creates stereotypes in which all meth addicts are put into one category and identifiable by the characteristics of the meth addict portrayed in the ads. In turn, the participants feel the community perceives meth addicts as the 'deviant enemy.' Based on what they see and hear in the ads, the participants believe the community considers them violent monsters and lepers to be feared. In essence, the war on meth feels more like a war on the meth addict, to these participants.

The findings suggest that the campaigns stereotyped image is embedded in the self-concept of the participants. Despite attempts to stray from the identity, they feel others continue to define them on the basis of the stereotype. They seem themselves as being identifiable by the characteristics portrayed in the ads and thus, the stigmatized image has been applied to them personally. The stigma is internalized. Further, the stigma of being a meth addict is evident in their views regarding interactions within the community: they believe they have experienced rejection, judgment and differential or prejudiced treatment. The findings indicate that in response to this, the participants exhibit shame, fear and expectations of judgment and unfair treatment. As such, they engage in stigma-coping strategies such as hiding their identity. All in all, these elements epitomize the idea of stigmatized shaming and a perceived stigma is apparent which could be detrimental to the reintegration of these participants. Further, these findings 
imply that the significance of the bonds created by the recovery bubble may be diminished in light of the negative societal reaction the participants perceive in connection with the campaign.

These findings offer several contributions to the literature. In terms of the theory of reintegrative shaming and labeling as a constructive process, the findings offer partial support. The theory suggests that a label or stigma is only constructive when it is associated with the acts of deviance of an individual and not the innate attributes of the individual (Braithwaite 1989; Furst et al. 1999; Goffman 1963). Under such conditions, respect for the individual remains intact and disapproval is focused on their behavior rather than their identity (Braithwaite 1989). This study found a belief among the participants that the campaign has created awareness of the meth problem, which has in turn created an understanding of the destructive nature of meth addiction. For example, it is believed that people look at the ads and realize this is what the addiction does to people and helps them to understand that these people are not inherently bad people but acted as such because of the addiction.

Within such a climate, Braithwaite's Shaming Theory suggests the offender is provided understanding and the opportunity to overcome shame by engaging in socially acceptable self-reinforcing behavior to win back the respect of the community (Braithwaite 1989; Furst et al. 1999). The campaign appears to paint this picture for the participants. They believe the campaign creates a climate of understanding and this belief is reflected in their experiences of empathy, acceptance and support from the community.

In line with past studies, however, the findings tend to support theory that labeling creates a barrier to reintegration because the label is associated with the individual as a 
deviant rather than the act of deviance. According to labeling theory, this type of negative labeling creates the basis for which stereotypes are formed (Becker 1963; Faupel et al. 2004). The stereotypes link a person to a set of undesirable characteristics and they are branded as a deviant. This places the 'deviant' in the position of an outsider. From the primary perspective of the participants, this appeared to be the case. The participants felt as though the campaign created stereotypes of meth addicts as drug-crazed violent monsters that steal and inflict harm on others. Portrayed in this manner, the campaign gives the impression that meth addicts pose a dangerous threat to the community. They are the deviant enemy and they should be feared. From the perspective of the participants, the campaign definitely made this impression on the community. The participants felt that as a result of this impression, the community did in fact look down on and fear meth addicts. This theme falls in line with Braithwaite's theory of shaming that suggests shaming is not reintegrative when it is degrading and disrespectful. This type of shaming is called stigmatization. A stigma is born in the eyes of the participants and the stigma is experienced among the participants. This finding also provides support for Buchanan and Young's (2000) study, which suggests that 'War on Drugs' policies and propaganda demonize drug addicts. As their findings suggest, this leaves problem drug users feeling rejected and stigmatized because they recognize the low status they are ascribed and are acutely aware of the negative stereotypical roles attributed to them. Buchanan (2004) refers to this as the Wall of Exclusion. Essentially the Wall of Exclusion is,

"A barrier that makes it extremely difficult for recovering drug users to become accepted into the structures and networks of everyday life. The propaganda designed to deter people away from trying illegal drugs by 
portraying drug users as a deviant enemy leads to a war on drug users themselves. This results in discrimination at every level. For many drug users, relapse is not attributable simply to physical craving or change in motivation but as a consequence of their frustration at trying to break into mainstream community life and finding themselves constantly shunned and excluded. At the very time when recovering drug users need assistance and support from the non-drug-using population to establish alternative patterns of social and economic life, they are often prevented by the wall of exclusion (134)."

The 'wall of exclusion' is evident in the findings of this study as the perceived stigma among the participants and related experiences of judgment, differential treatment and rejection attest to. Further, these experiences support several other studies, which found that individuals feel they are treated differently and socially excluded on the basis of a stigmatized identity (Astone 1982; Braithwaite 1989; Buchanan and Young 2000; Finklestein 1994; Lindsey et al. 2006; Link and Phelan 2001; Link et al. 1997; Semple et al. 2005).

On the basis of perceived stigma and experiences of stigma, the participants expressed fear and expectations of being judged and treated differently based on their stigmatized identity as a meth addict. In accordance with this, the participants engaged in stigma-coping strategies such as hiding their identity. This supports what Link and Phelan (2001) found in a study of stigma and the dual diagnosis of mental illness and substance abuse:

Once a stereotype is in place, it can affect labeled persons in important ways that do not involve obvious forms of discriminatory behavior on the part of people in the presence of the stigmatized person. The labeled person forms expectations about how people will respond to stigma and if one believes others devalue and reject people with stigma, they must now fear this rejection applies personally (367). 
Thus, whether or not the stigma actually exists in the world, the fact that the participants believe it does, has led them to expect and fear judgment and rejection. These findings provide support for an abundance of research regarding expectations, fear and resulting isolation connected to the stigmatization process (Buchanan and Young 2000; Evard 1971; Faupel et al. 2004; Finklestein 1994; Linsey et al. 2006; Semple et al. 2005; Link et al. 1997). Further, these findings provide support for Link and Phelan's (2001) concept of the stigmatization process. Link and Phelan (2001 [in Semple et al. 2005:368]) identified three components of the stigmatization process:

1) Culturally Induced Expectations of Rejection: beliefs that people develop regarding whether they will be rejected, devalued, and perceived as less worthy because they are identifiable by particular characteristic. It is anticipated and expected and can occur without ever having experienced direct mistreatment by others. This dimension is similar to the internalized stigma posed by Goffman.

2) Experiences of Rejection: actual experiences in terms of differential treatment or judgments.

3) Stigma-coping Strategies: hiding identity to avoid negative reactions.

The findings of this study support Link and Phelan's conceptualization of the stigmatization process. Further, the findings suggest that the stigmatization process is partially manifested by the campaign. The campaign has created a climate in the worldview of the participants that stigmatizes and isolates them from mainstream society through fear and expectations of judgment. The significance of the 'recovery bubble' to these participants is not surprising in light of such a climate. The 'recovery bubble' provides what the mainstream world appears to lack: strong social bonds and an element of reintegrative shaming. This provides support for the sub-cultural component of labeling theory, which suggests that addicts 'reject their rejectors' and turn instead to a 
subculture of like-minded people who are similarly rejected by the wider culture (Adler 1993; Braithwaite 1989). In essence, they experience fear of rejection, they feel they cannot risk being honest with outsiders and turn instead to other individuals who are in the same boat and offer understanding rather than judgment. The interesting component of this subculture, however, is that it is a reformed deviant population. They do not engage in deviance but rather try to navigate the conventional world together in a 'bubble.' The problem is that the bubble will not protect them from the outside world at all times, especially recovering addicts who are attempting to venture back into the mainstream world. As Link et al. (1997) found recovering addicts may be unable to reap the long-term benefits of treatment due to the stigmatization they encounter when they reenter the mainstream world. Further, Buchanan and Young (2000) contend,

Once a drug user is stable or drug free, they need to establish new routines and relationships not centered on drug taking. Without this reorientation, reintegration will be difficult and relapse likely. However, integration of recovering drug users into mainstream community life may not be helped by government rhetoric that presents drug users as a serious threat to families and communities. This reinforces isolation and discrimination towards people who develop illicit drug problems and tends to ghettoize them within drug subcultures with few exit routes to mainstream society (416).

It can only be presumed that the Montana Meth Project results in a greater push toward a subculture of recovering drug addicts, in the form of a recovery bubble. However, what is truly significant is that the campaign has clearly had an impact on the worldview of these participants, incorporating labels such as 'monster' and 'leper' into their self-concept and permeating their expectations of others in such a way that may hinder their reintegration. This finding contributes to a serious gap in the literature 
pertaining to the impact of scare campaigns on unintended audiences and suggests a need to fill the gap. As Buchanan alluded to, war on drugs propaganda creates a war on drug users because they portray the drug user as the enemy, yet the literature regarding this impact is virtually nonexistent. The findings of this study suggest that there are consequences of such campaigns particularly with regard to stigmatization. Given the implications of stigmatization, this provides a sound argument for addressing the gap in the literature and enhancing our knowledge regarding the role of scare campaigns in the stigmatization and reintegration of drug addicts.

\section{Policy and Program Relevance}

This study revealed that the Montana Meth Project exposes addicts to a process of stigmatization that may hinder their social reintegration. This has practical applications as it illuminates ways that social agencies can act as a buffer for the process of stigmatization that occurs in conjunction with the campaign. For example, campaign efforts and recovery programs could focus on counteracting stereotypes created by Montana Meth ads; educating the public about the nature of meth addiction and promoting a more healthy and non-judgmental understanding of the problem. In essence, the study could be used to combat the wall of exclusion created by the campaign. Then again, the study could be used to support the abolition of the Meth Project altogether. As Buchanan argued (2004:136), "if the drug problem is going to be successfully tackled then the wall of exclusion, partly constructed through tabloid shock horror campaigns and populist government propaganda, will need removing."

On the other hand, the study could be used to inform the Montana Meth Project of its implications in such a way that would promote alternatives to the use of "shock 
tactics' in future design and implementation. This would not only be beneficial to meth addicts but would aid in the campaigns objective as well. According to various studies, a softer approach is more effective than scare tactics with regard to the intended population (i.e. non-users, first-time users). In other words, emphasizing mild consequences such as social implications and emotional trauma is more effective in reaching first-time users and non-users than emphasizing extreme immediate consequences such as drug-induced health problems and violent behavior (Crano and Burgoon 2002; Varshavsky 2003). Further, the findings of this study in conjunction with previous research (Buchanan 2004; Faupel et al. 2004), suggest that scare tactics are detrimental to the unintended population of addicts due to the stigmatization that occurs. The culmination of these two factors suggest that changing their tactics would not reduce the stigmatized shaming of the unintended population of meth addicts but provide a more effective means of prevention among the intended population. In essence, a softer approach would have a more multifaceted and significant impact on the meth problem as a whole than the current tactics used. Further, given the potential duplication of the Montana Meth Project in other states, this study could help such states make an informed decision as to whether or not they should implement the program and perhaps give these states template with which the program could be tweaked to be more effective and less stigmatizing.

The findings of this study could be informative not only in terms of the campaign, but the general approach of drug programs and policies surrounding methamphetamine. Consistent with Buchanan's (2004) findings, this study suggests that the 'War on Drugs' becomes a 'War on Drug Users,' at least in the eyes of these participants. In an effort to prevent methamphetamine use, drug policies and programs should be conscious of the 
impact the 'war on meth' ideology has on the meth addict. The use of tactics that portray the meth addict, as a deviant enemy should be reevaluated given the consequences this has on the identity and reintegration of meth addicts. As Buchanan (2004) suggested, "In environment frightened with powerful moral and legal reactions to the use of drugs, the stigma attached to drugs may come to be a more important factor than the biology of addiction. The demonization of drugs and the criminalization of the drug user (i.e. war on drugs) could be more damaging to the individual and society than drug use or addiction itself (123)."

Thus, this should be taken into account in our efforts to fight the war on meth and the war on drugs in general. Further, such efforts should consider implementing some form of reintegrative shaming in their efforts to fight the war on meth. For example, programs could be designed that model a recovery bubble, promoting attachments and commitments to the conventional world and offering ceremonies of forgiveness and apology. As this study suggests, the ideology behind recovery programs such as NA and AA promotes reintegrative shaming and offers the elements that social bond theory deems necessary for a successful reintegration. However, as this study also suggests, such a bubble does not suffice in light of negative societal reactions. Thus, there could also be steps taken on the part of communities and perhaps in conjunction with the Montana Meth Project to reduce negative societal reactions. For example, community meetings and discussions held by the Montana Meth Project could include the help of recovering meth addicts in the war on meth. If recovering meth addicts were considered part of the solution, this could reduce the community's perception of these people as the deviant enemy and make the recovering addicts feel involved and important in the conventional realm rather than feel as though they are the deviant enemy. Together, if the recovery ideology of such programs as NA and AA were implemented on a larger 
scale outside of the recovery bubble and combined with efforts to reduce negative societal reactions, we might see some promise in the successful social reintegration of meth addicts. Through such efforts as these, we could accomplish our long-term goals of decreasing the number of addicts in the meth world and increasing the number of addicts participating in conventional society.

\section{Study Limitations}

There are several limitations that should be addressed with regard to this study. First, the study is not representative of the population of recovering meth addicts in Montana. For this study to be representative of recovering meth addicts in Montana, it would have been necessary to conduct research in more than one Montana community. Unfortunately, the scope of this study doesn't permit the time and money that would be required to conduct the study in more than one community.

Additionally, there is a sampling bias in that the study is only reflective of addicts in recovery. Addicts in recovery may not have the same outlook on the Montana Meth Project as those who continue involvement. Thus, the Montana Meth Project may affect those still involved differently and in ways vital to a holistic understanding of how public service campaigns affect unintended populations. The stigma may be the very reason they are not in treatment and attempting to recover. Thus, if the views of this population are not included we are missing a crucial piece of the puzzle. While these limitations have been recognized, it is argued that the data on recovering addicts are no less important. Unlike active users, recovering addicts are reentering the mainstream world and may encounter more societal reactions to their identity and therefore a heightened sense of stigma. Thus, their accounts may be very rich in observations and experiences, 
some of which active users might not have due to lack of involvement in conventional world. Further, the accounts of recovering addicts may be more reliable than those that are still using. Given the paranoia and distortion that can be associated with using meth, active meth users may give inaccurate accounts of their experiences, whereas recovering meth addicts may have a more accurate perception of their reality given that they are clean and the effects of using do not have to be accounted for.

Another limitation of the study is its inability to determine how much of the participants views regarding a perceived stigma can actually be accounted for by the campaign. It is possible that their views of perceived stigma stem more from the community or personal social interactions than from the campaign. Although there is compelling evidence that the campaign accounts for some of these views, extensive conclusions about this connection cannot be drawn from this study. Further research would be required to make such an assessment.

Given these limitations, generalizations cannot be made about the worldview of all meth addicts in Montana on the basis of this study. However, the study does provide an understanding of the worldview of the addicts in this sample and in this particular community. Considering what little we know about the worldview of addicts as it pertains to public service campaigns, the knowledge gained from this small and unrepresentative sample acts as a valuable steppingstone in our understanding.

\section{Future Research}

This study looked at the impact of the campaign from the standpoint of recovering meth addicts. Thus, the implications of the campaign only go so far as the perceptions of these participants and the perceived stigma that exists among them regarding personal 
experiences and community reaction. Future research should explore whether or not the perceived stigma observed among these participants extends beyond their perception into a real stigma in the attitudes of the community as well as treatment by the community. To fully comprehend the impact of stigma on the reintegration of meth addicts, such research is crucial. Further, it is possible that such a stigma, perceived or real, already exists apart from the campaign. Thus, research should also examine the correlation between the attitudes and treatment of the community toward meth addicts and their exposure to the Montana Meth Project. Such research, in combination with the current study, would provide great insight into the true nature of the campaign's impact on meth addicts and their social reintegration.

Additionally, a longitudinal study could be conducted to determine the actual consequences of stigmatization on the reintegration of recovering meth addicts. We could look for the correlation between the existence and degree of stigma that exists among recovering meth addicts and the degree to which their reintegration has been successful. Further, while this study explored the experience of stigma among recovering meth addicts in treatment, research suggests that those still active in their addiction may have a different experience. As Semple et al. (2005) found, those in treatment are more likely to experience stigma than those still active in their addiction given that their identity is exposed as a result of their participation in recovery programs as well as their attempts to participate in the conventional world. Active meth addicts, on the other hand, are more secluded and given less contact with the conventional world, their identity is less likely to be exposed. Thus, the perspectives and experiences of active meth users as they relate to the campaign and its potential stigma may be different than recovering meth addicts. This 
should be explored, as it will provide insight regarding how the campaign and any related stigma may contribute to their decisions and attempts to reintegrate differently than recovering meth addicts.

Further, research should focus on a comparison between the campaign's significance in rural and urban areas. For example, the campaign may have a more significant impact on rural populations given that treatment programs are less available in rural areas and the ability to hide such an identity within a rural population would be more difficult. An exploration of the campaigns impact on these areas may illuminate a slightly different picture than the picture painted by this study, which was conducted in a fairly urban area of Montana. Given the implementation of the 'Meth Project' in other states, future research might also consider doing a comparative analysis across participating states to determine what other factors might play a role in exacerbating or ameliorating the impact of such campaigns.

\section{Conclusion}

This exploratory study provides preliminary evidence suggesting the Montana Meth Project does have an impact on the worldview of recovering meth addicts in Montana. The campaign's potential to have a reintegrative impact, as suggested in the narratives of a few of these individuals, is overshadowed by the major finding that the campaign has a stigmatizing impact on the worldview of recovering meth addicts. They are "that guy:" the guy Montana Meth Ads portray in the ads warning young people not to be like. The accounts of these individuals provide evidence that in their worldview others seem them as 'that guy' and they often feel they are 'that guy.' The implications of this finding are significant considering the consequences of stigma, the lack of 
literature on the subject of anti-drug campaigns and unintended populations, and the continued implementation of the Meth Project in other states. This study suggests a need for future research to further explore the impact of scare campaigns and the Meth Project in particular on 'that guy.' 


\section{References}

Adler, Patricia. 1993. Wheeling and Dealing: An Ethnography of an Upper-Level Drug Dealing and Smuggling Community. $2^{\text {nd }}$ ed. New York: Columbia University Press.

Anderson, D. Mark. 2009. "Does Information Matter? The Effect of the Meth Project on Meth Use Among Youths.” Retrieved April 2, 2010 (http://ssrn.com/abstract=1544004).

Astone, N.A. 1982. "What Helps Rehabilitation? A Survey of Research Findings." International Journal of Offender Therapy and Comparative Criminology 26: 109-120.

Becker, H.S. 1963. Outsiders: Studies in the Sociology of Deviance. New York: Free Press.

Braithwaite, John. 1989. Crime, Shame, and Reintegration. New York: Cambridge University Press.

-------2000. "Shame and Criminal Justice.” Canadian Journal Of Criminology: 281-298.

Buchanan, Julian. 2004. "Tackling Problem Drug Use: A New Conceptual Framework." Social Work and Mental Health 2:117-138.

---------Young L. 2000. "The War on Drugs: A War on Drug Users." Drugs: Education Prevention \& Policy 7:409-422.

Cooley, Charles Horton. 1902. "Human Nature and the Social Order." New York Subscribers: 88143.

Covey, Herbert C. 2007. The Methamphetamine Crisis. West Port, CT: Praeger Publishers.

Crano, William D. and Michael Burgoon. 2002. Mass Media and Drug Prevention: Classic and Contemporary Theories and Research. The Claremont Symposium on Applied Social Psychology. New Jersey: Lawrence Erlbaum Associates, Inc.

Crosbie, David. 2003. "News and Views.” Drug and Alcohol Review 22: 243-248.

Erceg-Hurn, David M. 2008. "Drugs, Money, and Graphic Ads: A Critical Review of the Montana Meth Project.” Society for Prevention Research 9: 256-263.

Evard, Franklin. 1971. Successful Parole. Springfield, Illinois: Charles C. Thomas.

Faupel, Charles E., Alan M. Horowitz and Greg S. Weaver. 2004. Sociology of American Drug Use. New York: McGraw Hill, Inc.

Finkelstein, Norma. 1994. "Treatment Issues for Alcohol-and-Drug-Dependent Pregnant and Parenting Women." Health \& Social Work 19:7-15.

Furst, R. Terry Furst, Bruce D. Johnson, Eloise Dunlap, and Richard Curtis. 1999. "The Stigmatized Image of the 'Crack Head': A Sociocultural Exploration of a Barrier to Cocaine Smoking Among a Cohort of Youth in New York City." Deviant Behavior: An Interdisciplinary Journal 20: 153-181. 
Goffman, Erving. 1963. Stigma: Notes on the Management of a Spoiled Identity. Englewood Cliffs, NJ: Prentice-Hall.

Glaser, Barney G. and Anselm L. Strauss. 1967. The Discovery of Grounded Theory: Strategies for Qualitative Research. New York: Aldine De Gruyter.

Hartwell, Stephanie. 2004. "Triple Stigma: Persons with Mental Illness and Substance Abuse Problems in the Criminal Justice System." Criminal Justice Policy Review 15:84-99.

Hawkins, J.D. 1979. "Reintegrating Street Drug Abusers - Community Role in Continuing Care." In Addicts and Aftercare - Community Integration of the Former Drug User, 1979 By Barry Brown. Thousand Oaks, CA: Sage Publications, Inc.

Hillhouse, Maureen P., Patricia Marinelli-Casey, Rachel Gonzales, Alfonso Ang, Richard A. Rawson. 2007. "Predicting In-Treatment Performance and Post-Treatment Outcomes InMethamphetamine Users." Addiction 102:84-95.

Hirschi, Travis and Michael R. Gottfredson. 1979. Understanding Crime: Current Theory and Research. Beverly Hills, CA: Sage Publications.

Hunt, Dana E. 2006. "Methamphetamine Abuse: Challenges for Law Enforcement and Communities." National Institute of Justice Journal 254: 24-27.

Inter-university Consortium for Political and Social Research. 2008. "County Characteristics 2000-2007 [UNITED STATES].” Ann Arbor, MI: Inter-university Consortium for Political and Social Research.

Johnson, Allan G. 2000. The Blackwell Dictionary of Sociology: A User's Guide to Sociological Language. $2^{\text {nd }}$ ed. Malden, MA: Blackwell Publishing, Inc.

Katz, E. and P. F. Lazarsfeld. 1955. Personal Influence: The Part Played by People in the Flow of Mass Communication. Glencoe, IL: Free Press.

Lancaster, Alyse R. 2004. "What Does Curiosity Really Do to the Cat? A Look at How Message Exposure Can Lead to Illicit Drug Trial Among College Students." Mass Communication \& Society 7:77-95.

Lindsey, Michael A., Wynne S. Korr, Marina Broitman, Lee Bone, Alan Green, And Philip J. Leaf. 2006. "Help-Seeking Behaviors and Depression among African American Adolescent Boys.” Social Work 51:49-58.

Link, B., T.C. Francis, E. Struening. 1989. "A Modified Labeling Theory Approach in the Area of the Mental Disorders: An Empirical Assessment." American Sociological Review 54:400-423.

--------E.L. Struening, M. Rahav. 1997. “On Stigma and Its Consequences: Evidence from a Longitudinal Study of Men with Dual Diagnoses of Mental Illness and Substance Abuse." Journal of Health and Social Behavior 38:177-190.

--------Jo C. Phelan. 2001. "Conceptualizing Stigma.” Annual Review of Sociology 27:363-85. 
Marshall, Catherine and Gretchen Rossman. 2006. Designing Qualitative Research. $4^{\text {th }}$ ed. Thousand Oaks, CA: Sage Publications, Inc.

Montana Attorney General's Office. (January 2007). "Methamphetamine in Montana: A Preliminary Report on Trends and Progress." Montana Department of Justice Retrieved September 29, 2010 (http://www.fvgroup.com/news/MT_AG_Report_Final.pdf).

Montana Attorney General's Office. (April 2008). "Methamphetamine in Montana: A Follow up Report on Trends and Progress." Montana Department of Justice Retrieved May 23, 2010 (http://www.doj.mt.gov/news/releases2008/20080331report.pdf).

Montana Meth Project (www.montanamethproject.org).

Montana Meth Project Newsletter (Spring 2006) 1:1-4. Retrieved December 1, 2006 (www.montanamethproject.org).

Montana Meth Project Newsletter (Fall 2006) 2:1-4. Retrieved December 1, 2006 (www.montanamethproject.org).

Neuman, William Lawrence. 2003. Basics of Social Research: Quantitative and Qualitative Approaches. $1^{\text {st }}$ ed. Needham Heights, MA: Allyn \& Bacon.

National Drug Intelligence Center. (March 2005). "Methamphetamine Drug Threat Assessment." U.S. Department of Justice. Retrieved September 29, 2010 (http://www.justice.gov/ndic/pubs11/13853/13853p.pdf).

National Institute of Drug Abuse. (June 2006). "Evaluation of the National Youth Anti-Drug Media Campaign.” Retrieved May 20, 2010

(http://www.drugabuse.gov/about/organization/despr/westat/\#reports).

National Institute of Drug Abuse. (September 2006). "Methamphetamine Abuse and Addiction." NIDA: Research Report Series. Retrieved September 29, 2010 (www.nida.nih.gov/researchreports/methamph/methamph.html).

National Institute of Drug Abuse. (September 2007). "Methamphetamine Addiction: Cause for Concern - Hope for the Future." Topics in Brief: National Institute on Drug Abuse. Retrieved September 29, 2010 (http://www.nida.nih.gov/tib/meth.html).

National Survey on Drug Use and Health. 2006. "State Estimates of Past Year Methamphetamine Use." The NSDUH Report 37: 1-4.

Office of Applied Studies. 2007. Substate Estimates from the 2004-2006 National Surveys on Drug Use and Health. Rockville, MD: Substance Abuse and Mental Health Services Administration.

Office of National Drug Control Policy. (July 2008). "State of Montana: Profile of Drug Indicators." Retrieved October 4, 2010 (http://www.whitehousedrugpolicy.gov/statelocal/mt/mt.pdf). 
Reinarman, Craig. 2000. "The Social Construction of Drug Scares." in Patricia A. Adler and Peter Adler (eds.) Constructions of Deviance: Social Power, Context, and Interaction. Belmont, CA: Wadsworth Publishing Co.

---------and Harry G. Levine. 1997. Crack in America: Demon Drugs and Social Justice. Berkley: University of California Press. and Dan Waldorf, Sheigla B. Murphy and Harry G. Levine. "The Contingent Call of the Pipe: Bingeing and Addiction among Heavy Cocaine Smokers." in Reinarman and Levine (1997) Crack in America: Demon Drugs and Social Justice. Berkley: University of California Press.

Semple, Shirley J., Igor Grant, and Thomas Patterson. 2005. "Utilization of Drug Treatment Programs by Methamphetamine Users: The Role of Social Stigma." The American Journal on Addiction 14:367-380.

Siegel, Larry. 2006. Criminology: Theories, Patterns and Typologies. $9^{\text {th }}$ ed. Belmont, CA: Thompson/Wadsworth.

Siebel, Thomas M. and Steven A. Mange. 2009. "The Montana Meth Project: 'Unselling' a Dangerous Drug." Stanford Law and Policy Review 20: 404-416.

Tongue, E. and D. Turner. 1988. "Treatment, Rehabilitation and Social Reintegration of Drug Dependent Users.” Bulletin on Narcotics 40: 3-19.

Vardi, Nathan. 2009. “The Drug Capitals of American.” Narcotics. Retrieved January 14, 2010 (www.Forbes.com).

Varshavsky. 2003. "Media Drug Prevention and Public Service Advertising: Evaluating the National Youth Anti-Drug Media Campaign.” MA Thesis 1-67.

Wartella, Ellen A. and Patricia A. Stout. "The Evolution of Mass Media and Health Persuasion Models." In Crano and Burgoon. 2002. Mass Media and Drug Prevention: Classical and Contemporary Theories and Research. Mahwah, NJ: Lawrence Erlbaum Associates, Publishers.

Williams, Terry. 1989. The Cocaine Kids: The Inside Story of a Teenage Drug Ring. New York: Addison-Wesley Publishing Co.

Yzer, Marco, Joseph N. Cappella, Martin Fishbein, Robert Hornick, Kirkland, Ahern R. 2003. "The Effectiveness of Gateway Communications in Anti-Marijuana Campaigns." Journal of Health Communication 8:129-143. 
Appendix A

Consent Form 
PORTLAND STATE UNIVERSITY
Portland State University

Department of Sociology

Exploring the Montana Meth Project on the Reintegration of Montana Meth Addicts

You have been asked to participate in a research study conducted by Jaysen Ferestad from Portland State University, Department of Sociology. The researcher hopes to learn more about the role of the Montana Meth Project in the lives of active and former meth users. This study is being conducted in partial fulfillment of the requirements for a Master's Degree. Thus, the study will be conducted under the supervision of Melissa Thompson from Portland State University, Department of Sociology.

You were selected as a possible participant in this study because your views and experiences may help to better understand the impact of the Montana Meth Project on meth users and former users. If you agree to participate, you will be interviewed for approximately 45 minutes, which will involve questions about substance abuse and your treatment experience. The interview will be recorded on audiotape in order to get an accurate picture of what you tell me in the interview.

While participating in this study, it is possible that you may feel uncomfortable, angry, sad, guilty, scared or embarrassed because of some of the questions asked. You don't have to answer any questions you don't want to and you can stop at any time. It is also possible that others become aware of your participation in this study and what you tell me in the interview. For instance, it is possible that individuals, such as family members, coworkers, employers or authorities may find about your prior drug use and treatment. However, I will take every precaution necessary to prevent this from happening. For instance, I will not record any information that could be used to identify you, such as your name, address or the location of this interview. Further, the audiotape of this interview will only be identifiable by case number and no other identifying information. Additionally, you will not be required to sign anything to prevent your signature from linking you to the study or anything you tell me in the interview. As a further precaution to prevent identification, however, do not use your name or the name of others while the interview is being recorded.

Anything you tell me in the interview will be kept private and confidential, which means it will be kept either in a locked filing cabinet in my personal possession for which only I will have a key or in a locked filing cabinet in a locked office at the PSU Department of Sociology, for which only I will have a key. In addition, if you found out about this project through a social service agency, no one from the agency will know what you say. Lastly, when I write or talk about what 


\section{PORTLAND STATE UNIVERSITY}

I learned in this study, I will leave out any identifying information so no one will be able to tell whom I am talking about. . If there is a breach of confidentiality and the things we talked about are revealed, these safeguards are in place to make sure nothing we talked about can be linked back to you or your identity.

And while I will do everything to protect your confidentiality, I am required by the state of Oregon to report any intended harm to self or harm to others including child, spousal or elder abuse. Child abuse, as defined by law, includes permitting a person under18 years of age to enter or remain in or upon premises where methamphetamines are being manufactured; or unlawful exposure to a controlled substance that subjects a child to substantial risk of harm to the child's health or safety.

For taking part in this study, you will receive a $\$ 5$ gift card and you will also benefit in that you will help to increase knowledge that may help others in the future. Your participation is voluntary. You do not have to take part in this study and it will not affect your relationship with Portland State University or your relationship with the agency through which you were informed about this research.

If you have concerns or problems about your participation in this study or your rights as a research subject, please contact the Human Subjects Research Review Committee, Office of Research and Sponsored Projects, 111 Cramer Hall, Portland State University, (503) 725$4288 /(877) 480-4400$. If you have any questions about the study itself, contact Jaysen Ferestad at the Department of Sociology, Portland State University, (503) 725-3958.

Your verbal consent indicates that you have read and understand the above information and agree to take part in this study. Please understand that you may withdraw your consent at any time without penalty and that by giving your verbal consent, you are not waiving any legal claims, rights or remedies. If you found out about this study through a service social agency, you know that taking part in this study has nothing to do with the care you get there. If you agree to take part or say no, they won't know and it won't matter. They will treat you the same. The researcher will provide you with a copy of this form for your own records.

Jaysen Ferestad

Department of Sociology

Portland State University

(503) 725-4288 
Appendix B

Interview Guide 


\section{Interview Guide}

F About the Montana Meth Project

$x$ Have you heard about the Montana Meth Project?

$x$ What do you know about it?

$x$ Have you seen or heard the meth ads? How often would you say you come across the advertisements? What was the last meth ad you saw?

$x$ What are your thoughts and feeling about the campaign? Advertisements?

$x$ As you probably know, the ads use portrayals of meth addicts to convey their messages. Do you think the portrayal of meth addicts in those ads, is accurate?

$x$ How do you think those portrayals shape the community's perception of meth addicts?

\section{F Impact of Montana Meth Project on Own Life}

$x$ Do you think the portrayal of meth addicts in the meth ads has impacted your life in any way?

$x$ Do you think the portrayal of meth addicts in the ads has had any influence on...

...how people in the community think of you OR treat you?

...how your (nonusing) friends and family think of you OR treat you?

$x$ Do you think the portrayal of meth addicts has influenced...

... what you share with people in the community about your identity as a

former meth user? affected how you feel about sharing your ... what you share with friends and family?

$x$ Do you think the campaign/ads have affected your experiences with others? For example, have the campaign/ads affected any of your relationships in any way? Or the way others act toward or around you?

$x$ What is your relationship with these people? (e.g. the public, friends, family, neighbors, acquaintances, coworkers, employers, teachers, etc.) How do you feel about that?

$x$ If you could give people one piece of advice to encourage them not to use, what would it be?

\section{F Reintegration}

[Recovering]:

$x$ Tell me a little about your experience as a meth user/addict?

$x$ When you were using, how long had you been using for? (e.g. months/years)

$x$ How often did you use meth, when you were using? ( e.g. \# days per month/months per year)

$x$ Of the people you are closest to, do any use meth? If so, how many? How many do not use meth?

$x$ What were your reasons for seeking treatment here? 
$x$ Did others play a role in your decision to seek treatment? If so, what is your relationship to them?

$x$ Did others help you in your attempt to seek treatment? If so, how did they help (e.g. financially, emotionally)? What is your relationship to them [these people]?

$x$ Can you describe what your treatment experience has been like?

$x$ Can you also tell me what recovery has been like for you outside of treatment, in your daily life?

$x$ What factors do you feel contribute the most to your recovery?

$x$ Have you faced any struggles or barriers to your recovery along the way?

$x$ If known by others, has your identity as a former user influenced your recovery in any way?

$x$ Do you think the MMP has impacted your recovery in any way?

$x$ What factors do you think would further aid in your recovery down the road?

$x$ What factors do you think would hinder your recovery down the road?

[Active]:

$x$ Tell me a little about your experience as a meth user?

$x$ How long have you been using for? (e.g. months/years)

$x$ How often do you use meth? (e.g. \# days per month/months per year)

$x$ Of the people you are closest to, do any use meth? If so, how many use? How many do not use meth?

$x$ Have you experienced any struggles or barriers related to your identity as a meth user?

$x$ Have you ever sought help for your use? [If so] what happened? [If not] have you ever thought about seeking help? Why or Why not?

$x$ If you were to seek help, what factors do you think would influence your decision? Can you tell me a little more about these things?

$x$ If you were to seek help, can you think of anything that might make it easier/harder for you? Can you tell me a little more about these things?

$x$ Can you think of anything you think would make the recovery process easier/harder if you were to seek help?

Demographics

X Age, Gender, Race, Marital Status, Children, Occupation, Income, Education

\section{F Anything else you would like to mention?}

\section{Thank you for taking the time to do this interview with me. Your time and generosity are greatly appreciated.}


Appendix C

Timeline 


\section{THESIS TIMELINE}

\section{Spring 2007}

April

- Submit Human Subjects Application to IRB

- May

- Revisions to Human Subjects application regarding active user population

- Resubmit IRB application with revisions

- Literature Review and Refining interview guide (submit any changes to IRB)

- Submit thesis proposal to committee for review

- June

- Submit thesis proposal for review by Sociology faculty

\section{Summer 2007}

June

- Meet with director of Turning Point to set up interviewing for summer

- Hear back from IRB regarding active user population

July - September

- Begin participant recruitment of treatment population

- If receive final approval from IRB, begin recruitment of active user population

- Data collection

- Literature Review

\section{Fall 2007}

September - December

- Data analysis

- Thesis writing (methods, lit review, begin findings, discussion, conclusion)

\section{Winter 2008}

December - February

- Take class in College of Urban and Public Affairs - practical application of Soc Data analysis

\section{Fall 2008}

February - April

- Complete draft of thesis and submit to committee for review

- Complete revisions of thesis and obtain final approvals from committee

- Schedule defense

- Thesis defense

*Due to personal hardship during this term, the aforementioned tasks to be completed Spring of 2008 were put on hold and have resumed as of 2013 
Appendix D

Illustrations 
Visual and Written Illustrations as presented in Montana Meth Advertisements
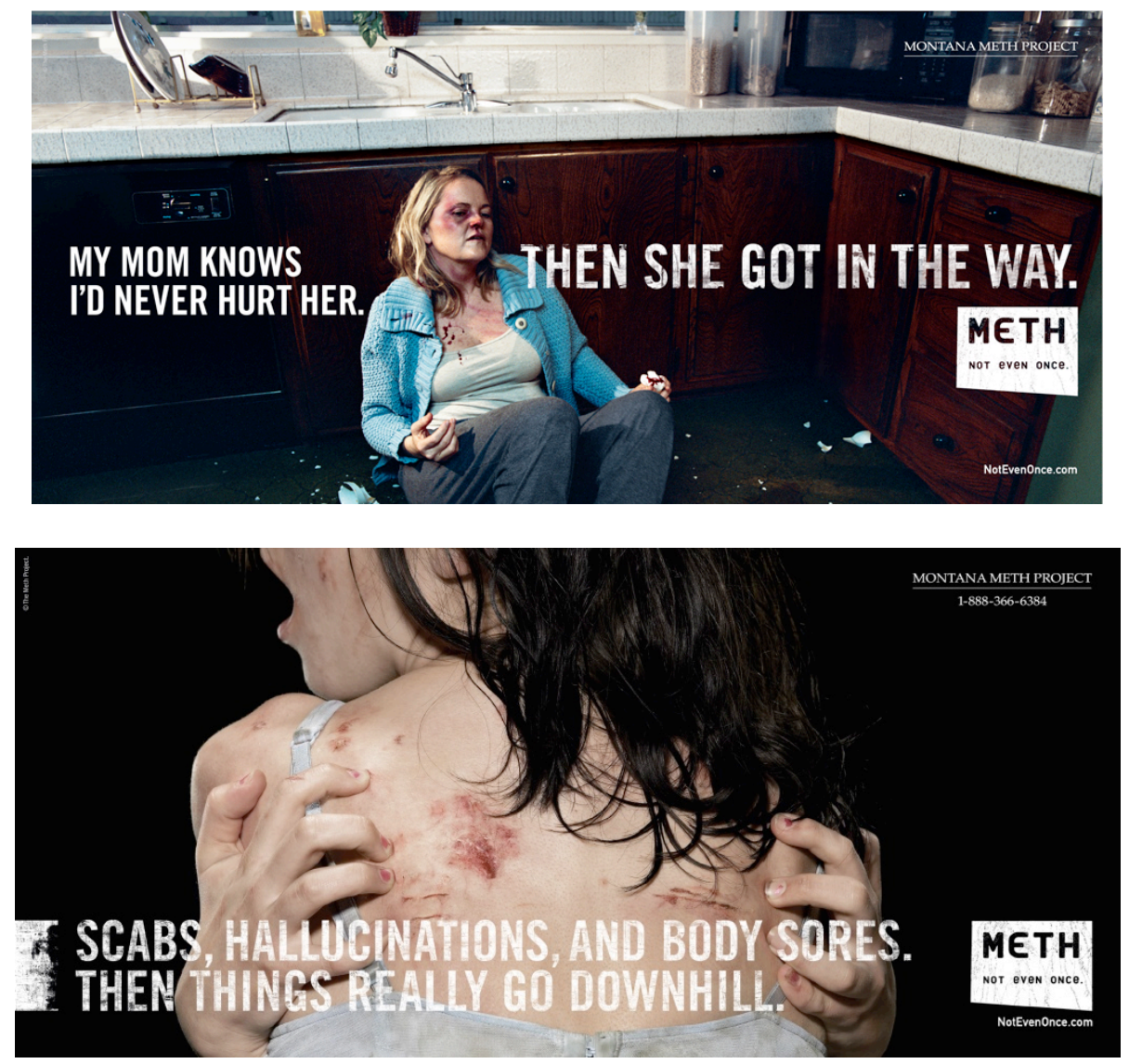

Bathtub - A teenage girl in her bathrobe talks on her cell phone while looking into her bathroom mirror. She says, "Yeah, my parents think I'm sleeping at your house". She hangs up and gets into the shower. While showering, she turns around and screams when she sees a pockmarked, bleeding version of herself shivering at the bottom of the shower, who pleads, "don't do it."

Laundromat - A deranged, addicted young man runs into a laundromat and demands the money of everyone inside, beating a man to the floor and screaming in the faces of women and children. He then runs to his pre-addicted self, grabs him by the collar, and shouts, "this wasn't supposed to be your life!"

Just Once - A teen girl declares that she is only trying methamphetamine "once", leading to a sequence of further compromises to support her addiction, each of which she 
promises will be "just once." The ad ends with her pre-teen sister stealing her methamphetamine and whispering "I'm going to try meth, just once."

That Guy - A teen boy states "I'm going to try meth just once, I'm not gonna be like that guy." He gestures towards a later version of himself, who deteriorates further, finally ending up shaking and sweating on a drug dealer's couch. A teen girl purchases from the dealer, saying "I'm gonna try meth just once, I'm not gonna be like that guy," indicating the now-wretched boy.

Junkie Den - In a shadowy drug den, a young boy tries methamphetamine for the first time. He is congratulated by dirty, drug-addicted people, who describe his future life as "one of us". One woman says that they will "shoot up together", two addicted men say that they and the boy will "steal together... and we'll be sleepin' together, too." The boy's protest that he is only trying it once is met with howls of laughter.

Crash - A car is driving in the rain at night. The tire explodes, and the car flips over. In narration, the teenage driver wishes that she had crashed on her way to "that party", even if she were to have broken her neck and become paralyzed, because it would have prevented her from trying methamphetamine. The girl, now addicted, smokes the drug in a dirty, run-down apartment, in which she says; "now this is my life."

Everything Else - A girl approaches a group of people who are using methamphetamine, and requests some for herself. The dealer gives her the drug, as well as "everything else" that comes with it. He aggressively saddles her with an intimidating drug dealer, "meth boyfriends" who rape her, an addicted baby, and in a mirror, he shows her bleeding "meth face."

Jumped - A younger teen boy is chased through a parking lot by three older males, who beat him to the ground and kick him. In narration, the boy wishes he had been assaulted that night, because then he would not have tried methamphetamine. The worst of the three raises a cinder block high over his head, threatening to drop it on the boy and crush his skull. The camera cuts to a drug den, where the boy, shaking, says, "Now all I do is meth."

Boyfriend - A teen girl lies on a bed in her underwear, as an older man zips up his pants and walks out the door of the motel room in which the girl lies. In narration, the girl states, "I love my boyfriend, we've been together since like 8th grade. He takes care of me." As the older man exits, he hands something to the boyfriend, who stands outside of the door. The boyfriend enters the room and shows the girl the bag of methamphetamine that the man gave him, as she cringes and weeps.

Mother - A teenage boy raids his mother's purse for money, while in narration, he talks about how much he loves her. When she enters the room and objects to his theft, both dismayed and concerned for her son, he strikes her to the floor. She cries out to him, hanging onto his leg. He kicks free and flees, as she lies sobbing on the floor. 
Friends - From the interior of a car, we see one worried passenger, the reckless driver, and a second worried passenger. A female narrator says that she is "tight with her friends", who "always look out for me". The narrator is revealed as the fourth person in the car, slumped in the backseat, as the car halts in front of a hospital emergency room. Her 'friends' pull her unresponsive body out of the car, dump her next to the curb, and speed off.

Parents - An upset teenage boy approaches his parents' house, knocking on the door, and shouting "I'm sorry, Dad!" In a narration, the boy talks about how he's always been really close with his parents. Inside the house, the parents are panicked and distraught, and turn off the light. The boy kicks the door many times, begging to be let in, screaming that he's going to kill them. 